\title{
Long-Term Creep Behavior of a CoCrFeNiMn High-Entropy Alloy
}

\author{
K.A. Rozman (D, M. Detrois, T. Liu, M.C. Gao, P.D. Jablonski, and J.A. Hawk
}

(Submitted August 7, 2020; published online September 17, 2020)

\begin{abstract}
The potential of high-entropy alloys (HEAs) to meet or exceed austenitic stainless steel performance with the additional benefit of improved hot corrosion/oxidation resistance makes FCC HEAs attractive for use in energy applications. While shorter-term creep tests have been reported in the literature on HEAs, not all methodologies utilize repeatable techniques. This manuscript reports on over 23,500 accumulated hours of tensile creep testing with adherence to ASTM standards on a melt-solidified ingot of CoCrFeNiMn HEA converted to wrought plate using conventional thermo-mechanical processing techniques. The typical standard creep analyses are reported, i.e., Larson-Miller parameter, Monkman-Grant relationship, activation energy for creep, and creep stress exponents were calculated and compared to previously reported short-term creep tests. Additionally, characteristics of creep fracture and microstructural evolution are reported with cursory dislocation mechanisms investigated.
\end{abstract}

Keywords creep, creep analysis, high-entropy alloy, SEM, TEM

\section{Introduction}

High-entropy alloys (HEAs), alternatively known as multiprincipal component alloys or composition concentrated solid solution alloys, have been studied intensively because they offer the potential of a good combination of mechanical and physical properties such as tensile strength, toughness, creep, wear and corrosion resistance that make them particularly interesting for use in extreme environments like those in the power generation industry. The National Energy Technology Laboratory (NETL) has a significant research history in HEAs with respect to modeling (Ref 1-11), alloy design (Ref 12-15), large-scale manufacture (Ref 2, 16, 17), mechanical behavior evaluation (Ref 2, 17-21), microstructural characterization (Ref $12,13,17,19,20,22-24)$, and ambient and high-temperature chemical response to environment (Ref 23-26) of HEAs. Specifically, NETL has focused HEA research on the possibilities of using HEAs in the commercial sector, i.e., the energy utilization sector, as structural materials. In that regard, NETL's efforts on modeling, while looking at wide ranging topics, still focus on what within these topics can be used at commercial scale, opposed to small $<1 \mathrm{~kg}$ melts of high-purity, experimental alloys. The combination of good yield stress and tensile strength with excellent ductility as measured by elongation and reduction in area as a function of temperature (similar to austenitic stainless steel) provided the first indication that these materials might be suitable as structural materials in energy

K.A. Rozman, M. Detrois, T. Liu, and M.C. Gao, National Energy Technology Laboratory, 1450 Queen Avenue S.W, Albany, OR 97321; and Leidos Reserach Support Tearm, 1450 Queen Avenue S.W., Albany, OR 97321; and P.D. Jablonski and J.A. Hawk, National Energy Technology Laboratory, 1450 Queen Avenue S.W, Albany, OR 97321. Contact e-mail: Kyle.Rozman@netl.doe.gov. applications. Now, verification by short- and intermediate-term creep testing also shows that this particular HEA behavior is indeed similar to various commercial austenitic stainless steels, making HEAs attractive when matching a particular chemical composition to a potential commercial energy sector component. In particular, because of the good ductility, and because HEAs perform similar to austenitic stainless steel in both tension and creep, HEA's could be used for tubing and piping in the boiler for a power plant.

Typically, a component might specify a particular strain limitation for a part as one measure of failure, e.g., let's say $\sim 1 \%$ creep strain over the expected lifetime of that component. While creep strain is a measureable entity, the factors affecting creep strain are more nebulous and mainly deal with the chemistry and overall stability of the microstructure. The stability of the microstructure is dependent on its chemistry and the possible phases that could form during manufacturing and long-term thermal exposure which are a result of the design approach and the effectiveness of the manufacturing process. The allure of HEA's has long been the potential stability of the alloy associated with the high entropy of the alloy (i.e., the initial selection of chemistry) and the assumed random (or more specifically, the quasi-random) nature of the atomic mixture of elements in the alloy. As such, it is important to consider the microstructural changes (especially undesirable phase formation) that might occur from thermal exposure of a HEA with superimposed mechanical stress.

For steels, long-term thermal exposure can lead to Z-phase formation which has been shown to cause premature failure in advanced martensitic-ferritic steels (Ref 27). On the other hand, in Ni-based superalloys overaging and rafting of $\gamma^{6}$ precipitates, and formation of TCP phases, are known to cause premature failure (Ref 28). Both these examples are caused by the inherent thermal microstructural instability in the alloys due to the chemical composition and manufacturing/heat treatment approach. Research into HEA stability has shown that some problems may exist. Pickering et al. (Ref 29) have shown that $\mathrm{Cr}$-rich $\sigma$ phase develops after $500 \mathrm{~h}$ at $700{ }^{\circ} \mathrm{C}$ in $\mathrm{CoCrFeNi}$ FCC alloy. Laplanche et al. (Ref 30 ) have examined $\sigma$ phase and determined that it has a tetragonal crystal structure with the 
following lattice parameters: $a=0.8766 \mathrm{~nm}$ and $c=0.45582 \mathrm{~nm}$. Cao et al. (Ref 31) have shown that a FCC $\mathrm{AlCoCrFeNiMn}$ alloy has a cubic crystal structure with a equal to $0.3606 \mathrm{~nm}$. Additionally, Otto et al. (Ref 32) have shown that a NiMn-rich phase forms as does a FeCo-rich phase after long-term isothermal exposure. The question naturally arises of how the development of these various phases affects creep behavior (primarily the creep life), say, for example, in the CoCrFeNiMn HEA system.

Otto et al. (Ref 32) performed 12,000-h (500 day) isothermal exposures on $\mathrm{CoCrFeNiMn}$ alloy. Otto et al. exposed three identical cylindrical ingots of $\mathrm{CoCrFeNiMn}$ alloy encapsulated in quartz in three identical tube furnaces at 500, 700, and $900{ }^{\circ} \mathrm{C}$. Results show that the alloy remains single-phase FCC up to $900{ }^{\circ} \mathrm{C}$, suggesting the entropy has a stabilizing effect which is not significantly affected by the increase in thermal kinetic energy. However, at lower temperatures certain phases precipitated out of the matrix. As previously noted, Cr-rich $\sigma$ phase formed at grain boundaries and at intergrain inhomogeneities. Additionally, a $\mathrm{Ll}_{0}$ structure rich in $\mathrm{Ni}$ and $\mathrm{Mn}$, and a $\mathrm{B} 2$ structure rich in $\mathrm{Fe}$ and $\mathrm{Co}$, were also reported to form along the grain boundaries. ThemoCalc simulations show $\sigma$ phase forming below $\sim 825^{\circ} \mathrm{C}$, as shown in Fig. 1 .

Such research has documented the relative stability of the FCC phase in CoCrFeNiMn systems during isothermal aging; however, much is unknown as to the stability of alloys of this type due to the compounding effect of stress in addition to the thermal load, i.e., long-term creep. While a literature search on creep of HEAs yields multiple reports, not all results are scientifically relevant. The literature of creep in high-entropy alloys (HEAs) is varied as to sources (alloy design and processing execution) and methods (indentation versus compression versus tension). Some authors use nano-indentation or small punch creep tests (Ref 30, 33-39). Others use stress relaxation techniques or compression to measure creep behavior (Ref 31). Many authors use small buttons, remelted, and then heat treated at some prescribed temperature for some arbitrary duration as the manufacturing approach (Ref 30, 3339 ) with inherent unreproducibility in the approaches. However, it is questionable as to the effectiveness of using these small melts in representing creep performance that might arise from larger ingots produced by typical manufacturing methods used for commercial components (Ref 40, 41).

The research discussed in this manuscript presents intermediate and long-term creep results on a CoCrFeNiMn alloy produced at NETL by industry-relevant manufacturing techniques. The CoCrFeNiMn alloy features a single-phase FCC microstructure without precipitates. (However, the particular variant reported within this manuscript had some Y-rich precipitates and some alumina inclusions which are discussed later.) The tensile results for the CoCrFeNiMn alloy have been reported previously, see Licavoli et al., (Ref 17), where tensile testing was carried out from ambient room conditions up to $800{ }^{\circ} \mathrm{C}$, using standard ASTM E- 8 practice. Tensile behavior shows good ductility throughout the range of temperature used with a decrease in yield stress from room temperature to $250{ }^{\circ} \mathrm{C}$ where it remained relatively constant through $600{ }^{\circ} \mathrm{C}$ at which point it decreased to $800{ }^{\circ} \mathrm{C}$ (Ref 17$)$.

This manuscript builds upon the tensile results of the HEAs (Ref 17), reporting on the intermediate to long-term creep behavior. A screening creep test (uniaxial tensile loading at $600{ }^{\circ} \mathrm{C}$ and $137.9 \mathrm{MPa}$ ) was initially used to assess the relative performance of a group of eight HEAs. One HEA chemistry

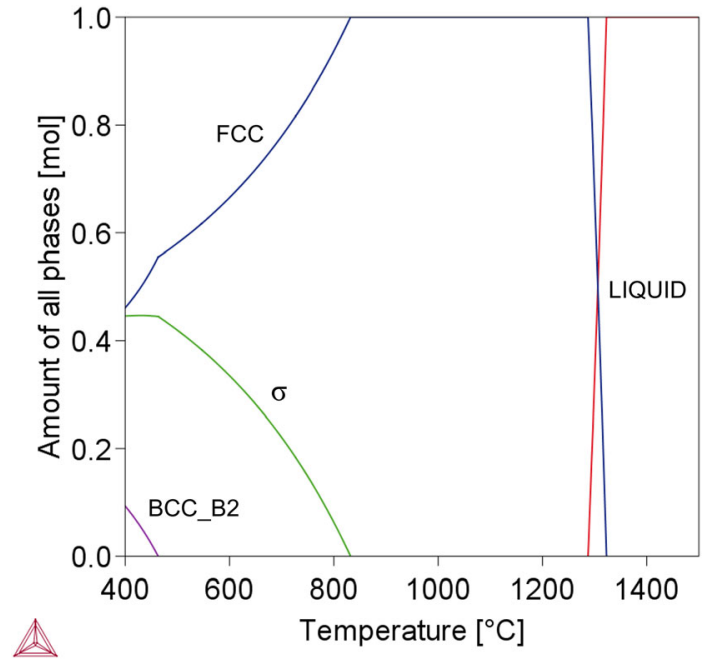

Fig. 1 Calculated phase diagram for equiatomic $\mathrm{CoCrFeNiMn}$ alloy

was selected from this group of eight for more comprehensive creep testing. In one series of creep tests, the temperature was established and the stress was varied. In the other series of creep tests, the stress was established and the temperature was varied. All specimens were tested to failure. Selected material was extracted from the gage and grip sections of the creep tested tensile bars for microstructure examination and assessment of microstructural stability.

\section{Materials and Methods}

\subsection{Material}

The following references (Ref 16, 17, 42-45) explain in detail the manufacturing process used to make heat resistant alloys, including details related to controlling minor elements ( $\mathrm{S}$ and $\mathrm{N}$, in particular) and the importance, and practicalities, of the homogenization procedure, especially as it relates to advanced heat resistant alloys. However, in general terms the manufacturing process and homogenization heat treatment can be described as follows for the CoCrFeMnNi alloy.

An alloy with the nominal composition of $\mathrm{CoCrFeMnNi}$ but with small amounts of intentionally added $\mathrm{Y}, \mathrm{Nb}$, and $\mathrm{C}$ was designed for vacuum induction melting (VIM). The $\mathrm{Nb}$ and $\mathrm{C}$ were added to the alloy to help facilitate the precipitation of carbide and other minor phases, while $\mathrm{Y}$ was added to reduce the $\mathrm{S}$ level in the alloy. The VIM furnace charge contained approximately $7.8 \mathrm{~kg}$ of feedstock in various forms, using commercial high-purity material (i.e., $99 \%$ pure with up to $1 \%$ impurities) where selected material was cold pressed into compacts that would fit into the VIM crucible. Note: NETL seeks to use industry relevant melting techniques, where data generated can be applied and then scaled to commercial manufacturing processes. Part of the feedstock consisted of a $\mathrm{Ni} 22 \mathrm{Cr}$ master alloy previously VIM manufactured to reduce $\mathrm{S}$. Slices of the master alloy plus compressed compacts of balancing feedstock and loose material were VIM processed at $1345{ }^{\circ} \mathrm{C}$ with additions of $\mathrm{NiCrY}$ to further decrease the concentration of $\mathrm{S}$ and $\mathrm{O}$ (Ref 45). The liquid metal was subsequently poured into 75-mm-diameter zirconia-coated graphite molds (to decrease $\mathrm{C}$ pickup from the mold). 
After casting, the hot top of the solidified ingot was removed after which a 5-mm-thick slice (approximately) was sectioned from the top of the ingot for chemical analysis. A Rigaku ZSX Primus II wavelength-dispersive $\mathrm{x}$-ray fluorescence (WDXRF) spectrometer with NIST traceable standards and reported accuracies to $0.01 \mathrm{wt}$. \% was used to carry out the bulk chemical analysis on the alloy. ASTM standard E1621 (Ref 46) was followed for WDXRF. A LECO CS444LS was used to determine $\mathrm{C}$ and $\mathrm{S}$ levels. Oxygen and $\mathrm{N}$ chemistries were determined using a LECO TC436AR. Both the $\mathrm{C} / \mathrm{S}$ and $\mathrm{O} / \mathrm{N}$ analyses were carried out using NIST certified standards with reported accuracy to 0.0002 wt. \%. ASTM E1019 (Ref 47) was followed for $\mathrm{C}, \mathrm{S}, \mathrm{O}$, and $\mathrm{N}$ determination.

The remaining ingot was given a custom homogenization heat treatment calculated using a combination of CALPHAD estimations and kinetic modeling. The objective of the homogenization heat treatment cycle was to reduce the residual chemical inhomogeneities inherent across dendrite arms (including the interdendritic regions) to within $\sim 1 \%$ of the nominal aim chemistry for each element (Ref 42, 44, 45).

After homogenization, the ingots were placed inside stainless steel foil pouches and heated to their thermo-mechanical processing (TMP) temperature. The stainless steel foil pouches were used to limit oxidation of the ingot during the thermal conditioning cycle prior to TMP. The ingots were held at the TMP processing temperature for $3 \mathrm{~h}$, i.e., enough time at temperature to thoroughly heat the center of the ingot. The TMP process temperature selected for this alloy was $\sim 860{ }^{\circ} \mathrm{C}$. The TMP steps consisted of upset forging, forge step reductions, and ingot squaring to create a rectangular shape suitable for hot rolling. Hot rolling into plate progressed with reheats between each rolling pass (calculated based on the varying thickness of the plate throughout the process). (Ref Note: The stainless steel pouches were removed prior to forging.) After the final hot rolling pass, the plate was returned to the furnace and held for $7 \mathrm{~min}$ to provide a full solution anneal (from a mechanical strength perspective) and to reduce residual stress due to TMP. Final thickness of the hot worked plate was approximately $10 \mathrm{~mm}$. Thermo-mechanical processing of the ingots in this manner produces a fully wrought product with a microstructure typical of rolled alloy product.

The design intent for this alloy was to have $\sim 20$ at. $\%$ of $\mathrm{Ni}$, $\mathrm{Co}, \mathrm{Cr}, \mathrm{Fe}$, and $\mathrm{Mn}$ with the other trace elements. Specific constituents analyzed by WDXRF are shown in Table 1. Other elements found by combustion analysis included $219 \mathrm{ppm} \mathrm{C}$ and values of $\mathrm{N}, \mathrm{O}$, and $\mathrm{S}$ below $20 \mathrm{ppm}$. The Fe content measured by WDXRF in this alloy fell short from the nominal composition (17.1 at.\%). However, X-ray electron dispersive spectroscopy (XEDS) did not verify this detriment of Fe (Table 1). The authors suspect the steel standards used to quantify the Fe content in the WDXRF may have lowered the measurement. The Fe content of steels is much higher than the 20 at.\% used for this HEA.

The initial microstructure consisted of a single-phase, FCC crystal structure. A representative transmission electron microscopy (TEM) micrograph is shown in Fig. 2(a). Note some thickness fringes are apparent on the TEM image, as shown in Fig. 2(a). Figure 2b shows a scanning electron microscopy (SEM) image overview of the grain size and grain structure. The ASTM grain size number for CoCrFeNiMn was 8.6. This corresponds to an average grain diameter of $18 \mu \mathrm{m}$. From Fig. 2b, Y-rich inclusions were observed. While addressed later in this manuscript, TEM has identified them as NiMnY phases and they appear as the bright phase in both Fig. 2(b) and (c). They are incoherent with the matrix. Further, these NiMnY inclusions appear cracked in the initial microstructure. Figure 2(c) shows another SEM image highlighting the relatively clean grain boundaries (i.e., no carbide or $\sigma$ phase). Also featured in Fig. 2(c) are NiMnY inclusions (top left and bottom right) with $\mathrm{Cr}_{23} \mathrm{C}_{6}$ carbides decorating the them. The initial grain boundaries were clean. The initial hardness of the asprocessed and heat-treated ingot was $130 \mathrm{~kg} / \mathrm{mm}^{2}$.

The individual elements are uniformly distributed throughout the microstructure (at least at the micron scale) for $\mathrm{CoCrFeNiMn}$. Inclusions found in CoCrFeNiMn using the SEM were primarily large, $\sim 10$ to $20 \mu \mathrm{m}$ and Y-rich. These Yrich inclusions appeared to be complex with backscatter contrast showing multiple phases. No trace of $\mathrm{Zr}$ inclusions was found in the material examined.

\subsection{Creep Test Methodology}

Creep tests were performed on ATS (Applied Test Systems, Inc.) creep frames with load capacity of $2270 \mathrm{~kg}$. The load was transferred to the specimen using a lever arm with a 20:1 ratio. Commercial ATS software provided a comma-separated data $\log$ of runtime, creep strain, left and right extensometer extension, thermocouple temperature, and load at 30-s intervals. Creep strain was measured from specimen shoulders using dual linear variable differential transducers. Creep strain was recorded using commercial data acquisition and control software provided by the vendor. Specimen temperature was measured using three thermocouples attached to the reduced section at equidistant intervals. Temperature variation along the length of the reduced section of the tensile specimen was less than $\pm 0.2{ }^{\circ} \mathrm{C}$.

Specimens for creep testing were machined from the 10mm-thick plate, parallel with the rolling direction. Specimen design utilized a reduced gage, rod-type cylindrical bar $76.2 \mathrm{~mm}$ in overall length. The mechanical test specimens had threaded ends, ANSI 3/8x16, with the gage diameter equal to $6.25 \mathrm{~mm}$. The parallel sided gage section was $31.75 \mathrm{~mm}$ in length. The profile radius was $6.35 \mathrm{~mm}$.

As mentioned previously, one series of creep tests was run at a constant temperature, i.e., $600{ }^{\circ} \mathrm{C}$, with the stress varied from 207 to $103 \mathrm{MPa}$ at equal stress increments (i.e., $\sim 17 \mathrm{MPa})$. A second series of creep tests was run at $137.9 \mathrm{MPa}$ with the temperature varied for each test from $650{ }^{\circ} \mathrm{C}$ to $575{ }^{\circ} \mathrm{C}$ at equal temperature increments (i.e., $12.5^{\circ} \mathrm{C}$ ). The creep tests were conducted in climate-controlled laboratory air with less than $50 \%$ humidity in general accordance to ASTM E139 (Ref 48).

Elongation at failure was determined from measurement of the broken specimens. An initial pre-creep measurement of sample length was made and recorded using the machined grooves where the extensometer is attached. After failure a second measurement is made, and the absolute elongation is determined. Likewise, the gage diameter is measured prior to testing and again after failure. This provides a way to calculate the reduction in area.

\subsection{Data Analysis Methodology}

Data reduction and point smoothing consisted of an algorithm that averaged time and strain over discrete time intervals that progressively increased with the duration of the test. For the first $2 \mathrm{~h}$ of the test, creep datum was averaged over $1 / 4 \mathrm{~h}$ intervals. For times between $2 \mathrm{~h}$ and $10 \mathrm{~h}$, the datum was 
Table 1 Elemental composition of CoCrFeNiMn alloy obtained from WDXRF, XEDS analysis (at. \%), and concentration of $\mathbf{C}, \mathbf{N}, \mathbf{O}, \mathbf{S}$ from combustion analysis (ppm)

\begin{tabular}{|c|c|c|c|c|c|c|c|c|c|c|c|}
\hline & $\mathbf{N i}$ & Co & $\mathbf{F e}$ & $\mathbf{C r}$ & Mn & $\mathbf{N b}$ & $\mathbf{Y}$ & $\mathbf{C}$ & $\mathbf{N}$ & $\mathbf{O}$ & $\mathbf{S}$ \\
\hline CoCrFeNiMn (WDXRF), at.\% & 21.0 & 20.3 & 17.1 & 20.5 & 20.2 & 0.07 & 0.76 & & & & \\
\hline CoCrFeNiMn (XEDS), at.\% & 19.8 & 19.3 & 19.6 & 19.5 & 19.8 & & & & & & \\
\hline CoCrFeNiMn (combustion/IR), ppm & & & & & & & & 219 & 19 & 19 & 14 \\
\hline
\end{tabular}
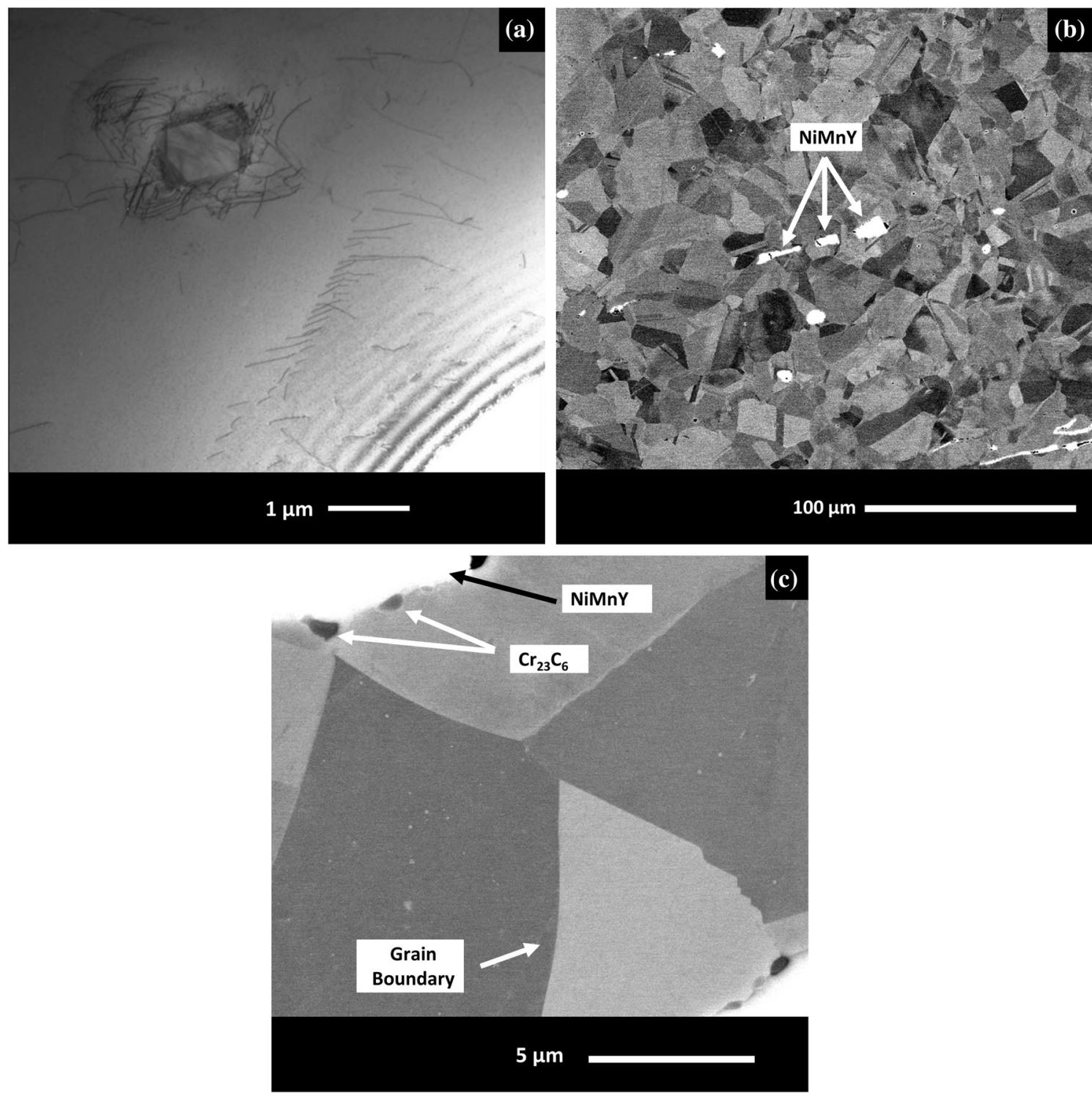

Fig. 2 Micrograph of initial microstructure for CoCrFeNiMn: (a) micrograph showing single-phase microstructure in the TEM, (b) micrograph showing grain and phase structure, and (c) micrograph showing grain boundaries and phase relationship within microstructure

averaged over $1 / 2$ - $\mathrm{h}$ intervals. For times between $10 \mathrm{~h}$ and $100 \mathrm{~h}$, the datum was averaged over 1-h intervals. Finally, for times greater than $100 \mathrm{~h}$ the datum was averaged over 5-h intervals. Data averaging included $50 \%$ overlap of datum with the previous data point. Strain rates were found by a linear fit of strain against time for the above intervals. The Larson-Miller parameter (LMP) was calculated for each specimen. See Eq. 1 for the LMP calculation.

$\mathrm{LMP}=T \cdot(\log t+C)$
In Eq. 1, $T$ is the creep test temperature in Kelvin, $t$ is the time to failure for the creep specimen in hours, and $C$ is the Larson-Miller constant (Ref 49).

\subsection{Microscopy Methodology}

A FEI Inspect F, scanning electron microscopy (SEM) was utilized to image the creep fracture surfaces. Unless otherwise noted the accelerating voltages used in the inspection of the fracture surfaces were $20 \mathrm{keV}$. Both secondary electron (SE) 
and backscatter electron (BSE) imaging modes were used in the inspection investigations. Standard metallographic procedures were utilized when cross sectioning the fractured creep samples. XEDS maps were generated for 2-h intervals at $20 \mathrm{keV}$.

For TEM three-mm-diameter rods were electrodischarged machined (EDM'd) from one half of each failed creep specimen. The extracted rods were sliced into disks approximately $0.7 \mathrm{~mm}$ in thickness. Each disk was ground down to between 120 and $130 \mu \mathrm{m}$, prior to electropolishing and/or ion milling. The disks were first electropolished using $100 \mathrm{ml}$ of $60 \%$ perchloric acid in $900 \mathrm{ml}$ methanol, at a temperature of $28{ }^{\circ} \mathrm{C}$. An electropolishing potential of between 17 and $25 \mathrm{~V}$ was established for CoCrFeNiMn. The electrolyte used was perhaps not particularly well suited to $\mathrm{CoCrFeNiMn}$ but was sufficient for revealing electron transparent regions.

TEM observations were initially made in a Philips/FEI CM200 and JEOL-2100PLUS operated at $200 \mathrm{kV}$. After initial TEM inspection of the polished foils, selected foils were then ion milled using a Gatan Precision Ion Polishing System (PIPS). The goal of this step was to expand the regions of electron transparent material.

Ion milling of the creep tested specimens was minimized whenever possible due to damage that accumulates in the volume exposed to highly energized Ar ion beams. In order to minimize Ar ion damage, a relatively low operating potential $(3 \mathrm{kV}$ ) was employed. Despite careful operation, some damage was expected and was sometimes present as dark speckled contrast in the bright-field (BF) images. The surface damage also provided additional spots in some of the zone axis diffraction patterns which were accounted for when conducting analyses. Energy-dispersive x-ray spectroscopy (EDS) analyses were also performed as needed using a Thermo-Fisher $\mathrm{LN}_{2}$ free, ultra-dry silicon drift detector (SDD) to assist in phase identification.

\section{Results}

\subsection{Creep Behavior}

The strain-time curves for the CoCrFeNiMn alloy are shown in Fig. 3 at both constant stress (Fig. 3a and c) and constant temperature (Fig. $3 \mathrm{~b}$ and d). The strain and strain rate versus time curves are plotted on a double logarithm plot. CoCrFeNiMn shows increasing strain with increasing creep time for both constant temperature and constant stress tests, but the general curve features are slightly different. Primary, secondary, and tertiary creep are observed in every instance. Note: The extensometer's maximum displacement is $12 \mathrm{~mm}$, which corresponds to a maximum strain of $\sim 34 \%$. About half the CoCrFeNiMn creep specimens exceeded 34\% strain, and as a consequence, the creep displacement versus time curves are truncated at long times where the overall creep strain exceeded $34 \%$.

At $137.9 \mathrm{MPa}$ (Fig. 3a and c), the minimum creep rate (MCR) is observed to decrease as the temperature decreases. At $600{ }^{\circ} \mathrm{C}$ (Fig. $3 \mathrm{~b}$ and d), the MCR is observed to decrease as the stress decreases. The time to MCR varied between $24.5 \%$ of lifetime at $207 \mathrm{MPa} / 600{ }^{\circ} \mathrm{C}$ and $1.7 \%$ of lifetime at 137.9 $\mathrm{MPa} / 625^{\circ} \mathrm{C}$ (see Table 2 and 3). This suggests $\mathrm{CoCr}$ FeNiMn alloy has a relatively short primary creep with secondary creep gradually transitioning into tertiary creep over a long time until final rupture.

Table 2 and 3 tabulate the relevant creep parameters from Fig. 3. Additionally, the Larson-Miller parameter is incorporated in the tables as calculated from Eq. 1. Creep specimens tested at constant stress are reported in Table 2 while those tested at constant temperature are given in Table 3. A minimum to maximum spread of the Larson-Miller parameter was observed to be 0.26 LMP for tests conducted at $137.9 \mathrm{MPa}$. Note: The Larson-Miller parameter is unitless and is reported in the thousands, e.g., divided by 1000 .

At constant creep stress with varying temperature, the MCR occurred at approximately the same time fraction $(1.7 \%$ to $6.3 \%$ of lifetime) and strain (0.24 to $0.64 \%)$. However, at constant temperature with varying creep stress, the MCR showed both stress and time dependence with the MCR occurring at $\sim 6 \%$ strain and $25 \%$ of life at $207 \mathrm{MPa}$, while at $103 \mathrm{MPa}$, the MCR occurred at $\sim 0.4 \%$ strain and $\sim 5 \%$ of creep life.

\subsection{Fractography}

The creep specimens failed predominately in a transgranular manner, with some intergranular secondary cracking. Representative SEM images of fracture surfaces at a variety of magnifications are shown in Fig. 4. At higher magnifications, as shown in Fig. 4(c) and (d), clear evidence of ductile failure is seen. Some secondary cracking is also evident on both the planar view (Fig. 4a) and the profile view (Fig. 4b). At high magnification, BSE contrast shows some heavier element precipitates at the base of ductile dimples, as shown in Fig. 9(c) and (d). Cracking was present (profile view) throughout the gage section as shown in Fig. 4(b).

\section{Discussion}

\subsection{Microstructure Analysis}

Inspecting the data for LMP in Table 2, one interesting trend emerges. Over the measured range as the LMP increases, the rupture stress decreases. However, at constant creep stress and varying temperature, some scatter in the LMP is observed. Evaluating the magnitude of the scatter, it was found to be $20.3029 \pm 0.0967$ for the tests performed at $137.9 \mathrm{MPa}$. This results in a coefficient of variation (COV) of only $0.48 \%$, which is quite small considering the normal variation in time to rupture of commercial alloys. While the scatter is rather small (in terms of COV), the fact that the LMP value continuously decreased as the time to rupture increased is significant and a sign the microstructure is not as stable as desired.

Select samples were cross sectioned and polished for thorough analysis. Additionally, samples from intermediateterm and long-term creep tests were prepared for TEM analysis. Analysis was performed in both the grip (no stress region) and gage (high stress region) sections.

The post-test microstructure is shown in Fig. 5 from a portion of the specimen gage section tested at $600{ }^{\circ} \mathrm{C}$ with $100 \mathrm{MPa}$ applied tensile creep stress. For this specimen, the time to failure was $4872 \mathrm{~h}$. Clear evidence of segregation of $\mathrm{Ni}$, $\mathrm{Co}, \mathrm{Cr}, \mathrm{Fe}$, and $\mathrm{Mn}$ is present from the EDS maps; see Fig. 5(b)-(g). Phases tended to form primarily along grain boundaries. Chrome enriched phases are present (see Fig. 5d) 

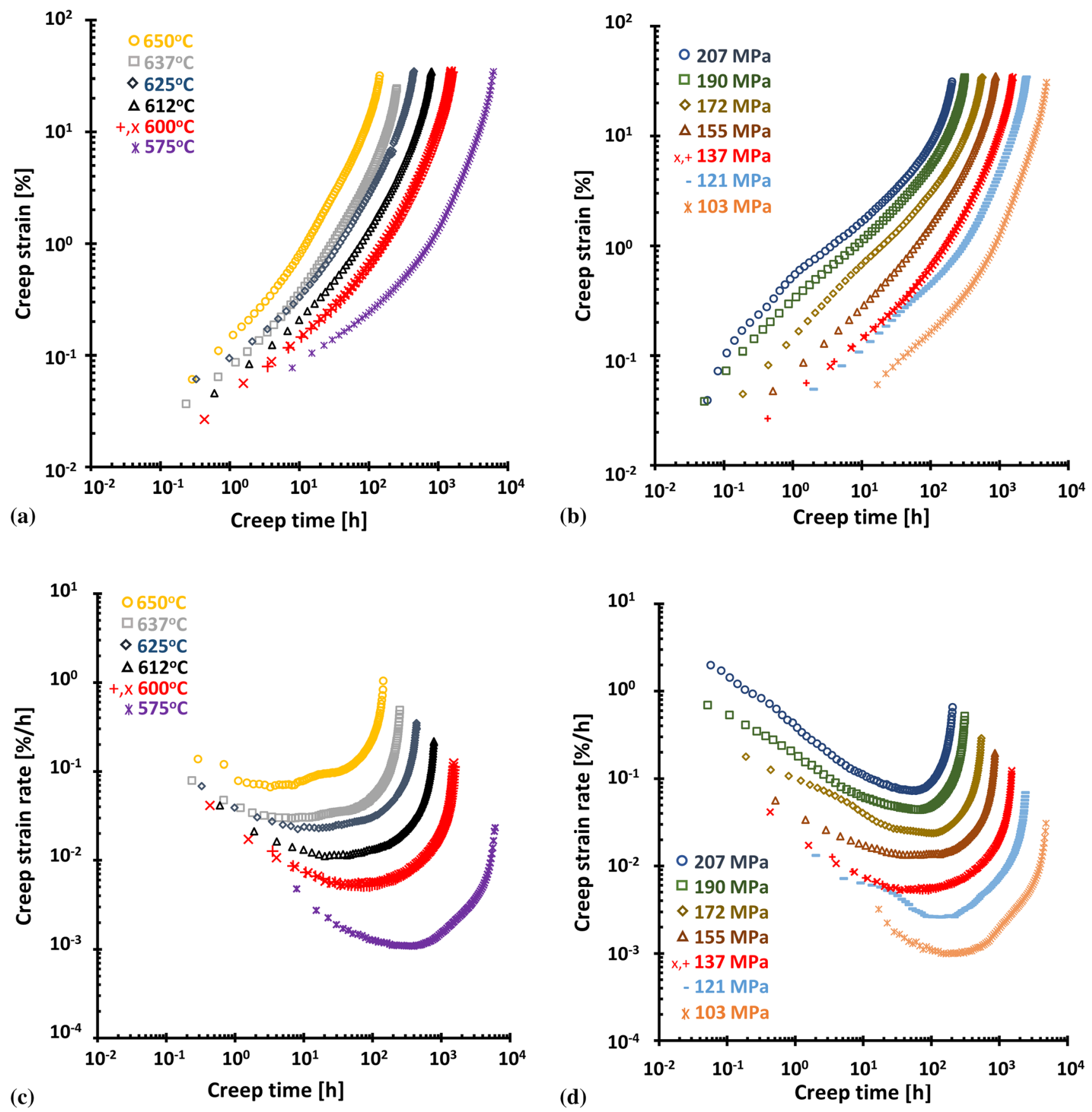

Fig. 3 Creep strain/creep strain rate versus creep time for CoCrFeNiMn: (a) and (c) Creep tests performed at constant stress of 137.9 MPa and various temperatures and (b) and (d) creep tests performed at constant temperature of $600{ }^{\circ} \mathrm{C}$ and various creep stress levels

with strong rejection of $\mathrm{Ni}$ and $\mathrm{Mn}$ as shown in Fig. 5(b) and (f), respectively.

In Fig. 6, TEM diffraction patterns identified both $\sigma$ and $\mathrm{M}_{23} \mathrm{C}_{6}$ Cr-rich carbides, with diffraction patterns inset in their relevant figures. The $\mathrm{Cr}_{23} \mathrm{C}_{6}$ was observed to have a FCC crystal structure with a lattice parameter of $a=1.05 \mathrm{~nm}$, while the $\sigma$ phase was observed to have a tetragonal crystal structure with lattice parameters of $a=0.872 \mathrm{~nm}$ and $c=0.453 \mathrm{~nm}$. These measurements agree with Laplanche et al. (Ref 30). Additionally, $\mathrm{Cr}_{23} \mathrm{C}_{6}$ was observed to have $\sim 86$ at. $\% \mathrm{Cr}$ while $\sigma$ had 47 at. $\%$ Cr. As TEM diffraction patterns are not available to identify precipitates on the SEM, the relative size of precipitates was used to differentiate them and $\mathrm{Cr}$ content was used to verify this assumption. Large ( $\geq 2 \mu \mathrm{m}$ ) blocky Cr-rich phases observable in the SEM were assumed to be $\sigma$ and verified by EDS point scans with $\sim 41-43$ at.\% $\mathrm{Cr}$ content, while smaller $(<2 \mu \mathrm{m}) \mathrm{Cr}$-rich phases only observable at higher magnifications are assumed to be $\mathrm{M}_{23} \mathrm{C}_{6}$ carbides. Due to their smaller size, quantification of $\mathrm{Cr}$ content was difficult and not reported in this manuscript. While $\mathrm{C}$ content could differentiate between $\mathrm{Cr}_{23} \mathrm{C}_{6}$ and $\sigma$, EDS in the SEM is known to not accurately measure $\mathrm{C}$. Therefore, $\mathrm{C}$ was not used as an identifier for $\mathrm{M}_{23} \mathrm{C}_{6}$ carbides. Some minor rejection of $\mathrm{Co}$ and $\mathrm{Fe}$ in the $\sigma$ phase is noted in Fig. 5(c) and (e).

In addition to $\mathrm{Cr}$ segregation, $\mathrm{Ni}$ and $\mathrm{Mn}$ were observed to segregate in the microstructure as well. Both NiMnY (Figs. $5 \mathrm{~g}$ 
Table 2 Creep results for specimens tested at a constant stress of 137.9 MPa

\begin{tabular}{|c|c|c|c|c|c|c|c|}
\hline $\begin{array}{l}\text { Temperature, } \\
{ }^{\circ} \mathrm{C}\end{array}$ & $\begin{array}{l}\text { Stress, } \\
\text { MPa }\end{array}$ & $\begin{array}{l}\text { Time to } \\
\text { failure, } h\end{array}$ & $\begin{array}{c}\text { Elongation, } \\
\%\end{array}$ & $\begin{array}{c}\text { Larson-Miller parameter/ } \\
1000, C=20\end{array}$ & $\begin{array}{l}\text { Minimum creep } \\
\text { rate, } \% / h\end{array}$ & $\begin{array}{c}\text { Time fraction to } \\
\text { MCR, } \%\end{array}$ & $\begin{array}{l}\text { Strain to } \\
\text { MCR, \% }\end{array}$ \\
\hline 650 & 137.9 & 145 & 35.4 & 20.45 & $6.68 \times 10^{-2}$ & 2.2 & 0.24 \\
\hline 638 & 137.9 & 255 & 31.3 & 20.40 & $2.99 \times 10^{-2}$ & 2.6 & 0.22 \\
\hline 625 & 137.9 & 469 & 44.2 & 20.36 & $2.24 \times 10^{-2}$ & 1.7 & 0.19 \\
\hline 613 & 137.9 & 822 & 30.0 & 20.29 & $1.11 \times 10^{-2}$ & 2.5 & 0.22 \\
\hline 600 & 137.9 & 1604 & 62.3 & 20.26 & $5.10 \times 10^{-3}$ & 4.1 & 0.48 \\
\hline 600 & 137.9 & 1556 & 29.5 & 20.25 & $5.27 \times 10^{-3}$ & 2.2 & 0.24 \\
\hline 588 & 137.9 & 2959 & 37.1 & 20.20 & $\mathrm{n} / \mathrm{a}$ & $\mathrm{n} / \mathrm{a}$ & $\mathrm{n} / \mathrm{a}$ \\
\hline 575 & 137.9 & 6408 & 42.3 & 20.19 & $1.08 \times 10^{-3}$ & 6.3 & 0.64 \\
\hline
\end{tabular}

Note: The extensometer failed for the specimen tested at $587.5^{\circ} \mathrm{C}$, and the time to failure was rounded to the nearest integer

Table 3 Creep results for specimens tested at a constant temperature of $600{ }^{\circ} \mathrm{C}$

\begin{tabular}{lccccccc}
\hline $\begin{array}{l}\text { Temperature, } \\
{ }^{\circ} \mathbf{C}\end{array}$ & $\begin{array}{c}\text { Stress, } \\
\mathbf{M P a}\end{array}$ & $\begin{array}{c}\text { Time to } \\
\text { failure, } \mathbf{h}\end{array}$ & $\begin{array}{c}\text { Elongation, } \\
\mathbf{\%}\end{array}$ & $\begin{array}{c}\text { Larson-Miller parameter/ } \\
\mathbf{1 0 0 0} \mathbf{C}=\mathbf{2 0}\end{array}$ & $\begin{array}{c}\text { Minimum creep } \\
\text { rate, \%/h }\end{array}$ & $\begin{array}{c}\text { Time fraction to } \\
\text { MCR, \% }\end{array}$ & $\begin{array}{c}\text { Strain to } \\
\text { MCR, } \%\end{array}$ \\
\hline 600 & 206.8 & 210 & 33.2 & 19.49 & $7.32 \times 10^{-2}$ & 24.5 \\
600 & 189.6 & 315 & 28.7 & 19.64 & $4.44 \times 10^{-2}$ & 20.1 \\
600 & 172.4 & 572 & 38.1 & 19.87 & $2.37 \times 10^{-2}$ & 17.5 \\
600 & 155.1 & 906 & 39.9 & 20.04 & $1.34 \times 10^{-2}$ & 5.5 \\
600 & 137.9 & 1604 & 62.3 & 20.26 & $5.10 \times 10^{-3}$ & 4.7 \\
600 & 137.9 & 1556 & 29.5 & 20.25 & $5.27 \times 10^{-3}$ & 2.2 \\
600 & 120.7 & 2495 & 32 & 20.42 & $2.62 \times 10^{-3}$ & 2.8 \\
600
\end{tabular}

and $6 \mathrm{~d}$ ) and NiMn (Fig. 5f and 6c) phases were observed. The NiMnY phase was retained from the initial microstructure. The NiMnY phase strongly rejected $\mathrm{Fe}$ and $\mathrm{Cr}$ and weakly rejected Co, see 'NiMnY' in Table 4, where chemistries were gathered in the SEM by EDS. The NiMn phase strongly rejected Co, Fe, and C, see 'NiMn' in Table 4. This phase is also reported by Otto et al. (Ref 50), who also reported on FeCo segregation. Such segregation is not as readily apparent as $\mathrm{Cr}$ or $\mathrm{Mn}$ segregation as shown in Fig. 5; however, some hints in denser areas of $\mathrm{Co}$ and $\mathrm{Fe}$ are apparent in Fig. 5, where one potential area is arrowed. EDS scans from this area show elevated Fe and Co levels at 21.3 and 21.0 at.\%, respectively. In an area away from the arrowed location, matrix concentrations of $\mathrm{Fe}$ and $\mathrm{Co}$ at 19.68 and 19.28 at.\%, respectively, are found. The WDXRF showed $\mathrm{Fe}$ and $\mathrm{Co}$ at 17.1 and 20.3 at.\%, respectively, suggesting the area may be enriched. Errors in measurement were not calculated because this phase has faint contrast and were difficult to locate and as such an insufficient number of measurements were taken for statistical significance.

From the grip section, the influence of temperature and time can be observed in a relatively stress-free environment. The same phase segregation is present in the grip section as in the gage section (not shown). Clear $\mathrm{Cr}$ segregation was noted in the grip section with similar chemistry profile, see ' $\sigma$ ' in Table 4, suggesting this phase is most probably $\sigma$. The NiMnY phase is also present in the grip section, with similar chemistry profile, see 'NiMnY' in Table 4. Only one particle of NiMn phase was found in the grip section, which was not analyzed. The FeCo phase was not found in the grip section.

While not observed at lower magnifications in the SEM, at high magnifications in the TEM, elemental matrix separation was detected. Some grains were found which were Ni- and Mnrich, and Cr-poor. These are denoted ' $m$ ' in Fig. 6(a). Additionally, $\sigma$ and $\mathrm{M}_{23} \mathrm{C}_{6}$ phases (Fig. $6 \mathrm{a}$ and $\mathrm{b}$ ) were identified using electron diffraction. These are marked as ' $\sigma$ ' and ' $\mathrm{Cr}$ ' in Fig. 6(a) and ' $\mathrm{Cr}_{23} \mathrm{C}_{6}$ ' and ' $\sigma$ ' in Fig. 6(b) and (d). The nominal equiatomic chemistry is identified by ' $\mathrm{M}$ ' for the grains in Fig. 6(a). The $\mathrm{Cr}$-lean grains were identified in proximity to $\mathrm{Cr}$ rich phases $\left(\sigma\right.$ and $\mathrm{M}_{23} \mathrm{C}_{6}$ ), as expected. It would appear that the Cr-rich phases evolve by depleting the adjacent grains of Cr. As such, a composite structure of nominally normal grains interspersed with $\sigma$ phase developed.

Segregation behavior has been seen before in commercial 9\% Cr ferritic-martensitic steels where Z-phase formed at long creep times (Ref 51, 52). A properly applied homogenization cycle has been shown to significantly increase creep life of various alloys by preventing or delaying detrimental phase evolution during creep (Ref 17, 43, 50). However, the attempt to homogenize these initial eight alloys, including the one under discussion, was based on using thermodynamic databases that were not established for HEA-type alloys. As such, it is not a surprise that $\sigma$ phase developed during creep of the CoCrFeNiMn alloy at relatively short times. Pickering et al. (Ref 29) showed $\sigma$ first precipitated at $500 \mathrm{~h}$ under isothermal 

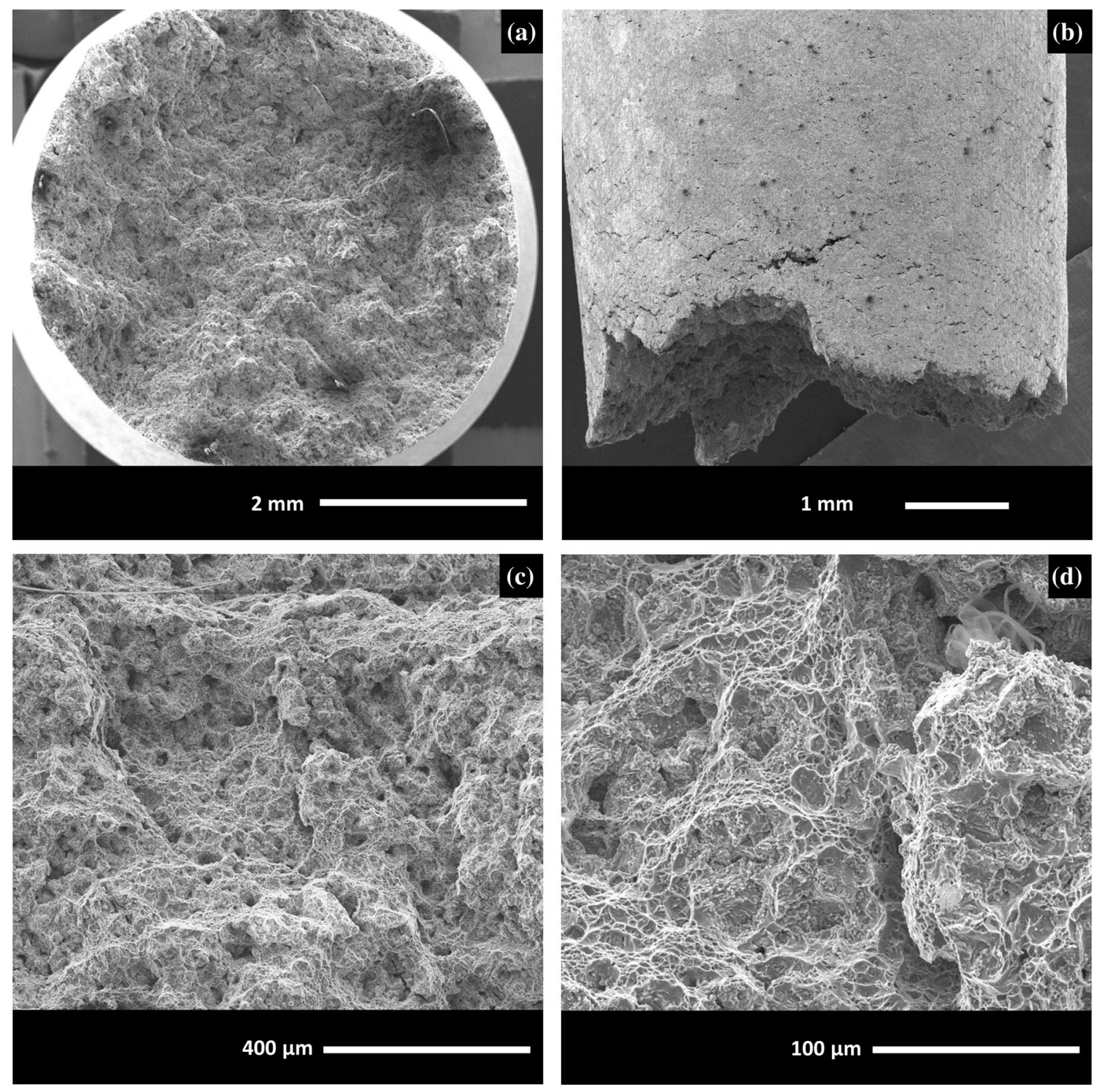

Fig. 4 Fracture surfaces from CoCrFeNiMn creep tested at $600{ }^{\circ} \mathrm{C}$ at $170 \mathrm{MPa}$ at several magnifications. (a) Overview, (b) profile view, (c) 250X magnification with secondary electrons, and (d) 1000X magnification with secondary electrons

aging conditions while Otto et al. (Ref 32) showed after $12,000 \mathrm{~h} \sigma$ has developed to a size scale of $1 \mu \mathrm{m}$. Thicknesses of Cr-rich phases in Fig. 5(d) range from 1-5 $\mu \mathrm{m}$ after $4872 \mathrm{~h}$. It was assumed that such rapid $\sigma$ phase evolution resulted as a by-product of sub-optimal homogenization of the as-cast ingot. Subsequent research has been done to refine the homogenization process, especially temperature and the time at temperature during the homogenization cycle.

\subsection{Creep Discussion}

4.2.1 Larson-Miller Analysis. The LMP plot is shown in Fig. 7(a), relative to other commercial alloys of interest, using a LMP constant equal to 20. Relative to superalloys Haynes 282 and 230, CoCrFeNiMn underperforms, while the CoCrFeNiMn performs better than P91 steel. These results were not unexpected. The creep performance of CoCrFeNiMn is close to that of 316 and $347 \mathrm{H}$ austenitic stainless steel (Ref 53) at lower LMP values (i.e., short-term creep tests).
Comparison of test conditions under constant temperature $\left(600{ }^{\circ} \mathrm{C}\right)$ with varying creep stress, or constant stress $(137.9 \mathrm{MPa})$ with varying temperature, is represented in Fig. 7(b). Note: In Fig. 7(b), a more accurate Larson-Miller for $\mathrm{C}$ was determined based solely on $\mathrm{CoCrFeNiMn}$ creep behavior. (The value of $\mathrm{C}$ was determined as 16.4; see subsequent discussion for details.)

While assuming a value of 20 for $\mathrm{C}$ is generally not a concern when comparing alloys (i.e., the goal is to observe the relative performance), universally applying it will lead to errors in projecting long-term failure estimation from short-term creep test data (Ref 54). Testing a series of samples at constant stress while varying the temperature allows the true value of $C$ to be determined for the Larson-Miller parameter. Performing a linear regression of inverse temperature against logarithm of time yields the true Larson-Miller constant (Ref 49), Eq. 2.

$\frac{1}{t_{r}}=A \cdot e^{-Q} / R \cdot T$ 

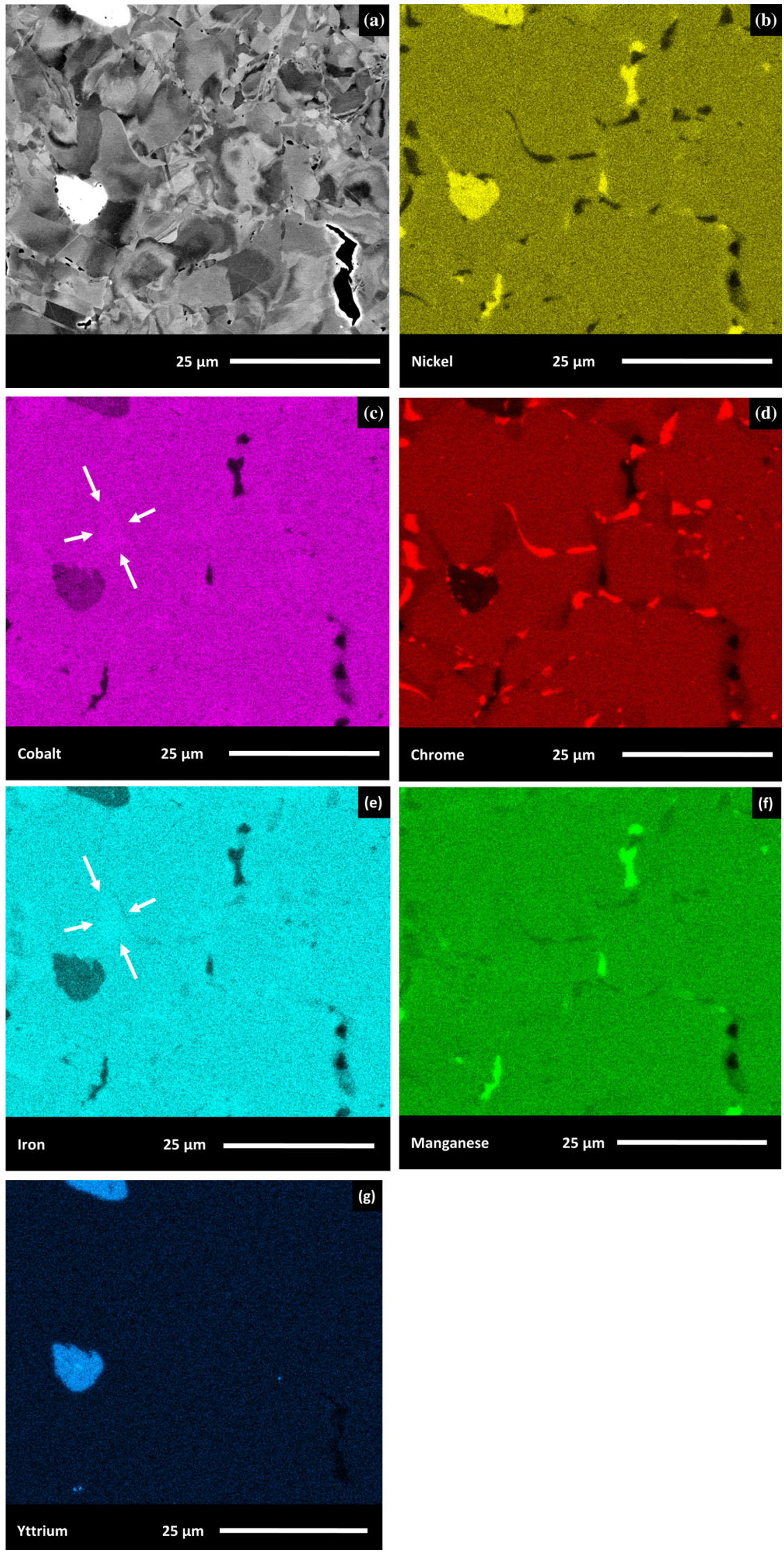

Fig. 5 EDS maps from the gage section of a specimen creep tested at $600{ }^{\circ} \mathrm{C}$ and $100 \mathrm{MPa}$. (a) Backscatter reference image, (b) Ni map, (c) Co map, (d) Cr map, (e) Fe map, (f) Mn map, and (g) Y map 

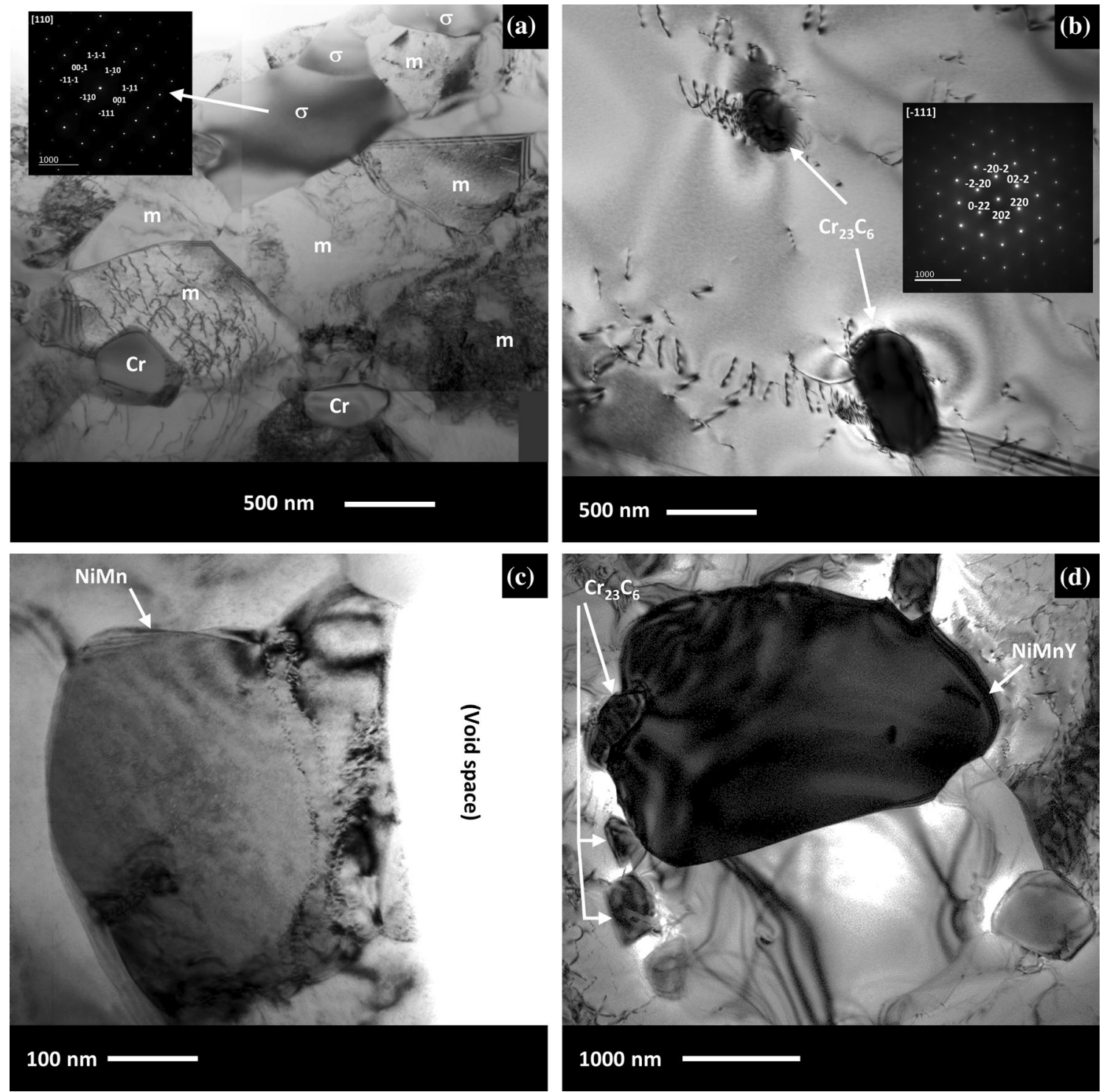

Fig. 6 TEM micrographs from a creep tested specimen at $600{ }^{\circ} \mathrm{C}$ and $207 \mathrm{MPa}$ : (a) Overview of grain structure with inset showing diffraction pattern of $\sigma$ phase, (b) example $\mathrm{Cr}_{23} \mathrm{C}_{6}$ carbide with inset showing diffraction pattern of $\mathrm{Cr}_{23} \mathrm{C}_{6}$, (c) example NiMn phase, and (d) example NiMnY phase

Table 4 Various phase compositions in at.\%, determined from EDS in the SEM or TEM from the gage or grip section of a crept specimen tested at $600{ }^{\circ} \mathrm{C}$ and $100 \mathrm{MPa}$

\begin{tabular}{llllllll}
\hline & Phase & Ni & Co & Fe & Cr & Mn & Y \\
\hline Gage & NiMnY & 36.49 & 13.98 & 9.33 & 8.2 & 22.32 & 9.09 \\
Gage & NiMn & 36.51 & 9.17 & 8.14 & 9.10 & 37.07 & - \\
Gage & $\sigma$ & 7.41 & 18.15 & 18.52 & 42.55 & 13.37 & - \\
Gage & $\mathrm{Cr}_{23} \mathrm{C}_{6}$ & 2.9 & 3.1 & 5.1 & 80.5 & 8.4 & - \\
Grip & $\sigma$ & 8.58 & 18.47 & 17.38 & 41.04 & 14.54 & - \\
Grip & NiMnY & 33.88 & 13.73 & 10.56 & 12.92 & 22.5 & 6.42 \\
\hline
\end{tabular}

In Eq. $2, t_{r}$ is the time to rupture, $A$ is a constant, $Q$ is the activation energy for creep, $R$ is the gas constant, and $T$ is the temperature.

A Larson-Miller constant of 16.4 was calculated as a result. A Larson-Miller constant of 17.5 was reported for Haynes 230
(Ref 55) and a constant of 25 is typically selected for steels. With a calculated constant of 16.4 , the constant is closer to solid solution strengthened nickel alloy than that of BCC steel. While not seeming to be relevant, austenitic stainless steel, ferritic-martensitic steel, and nickel superalloys form the 

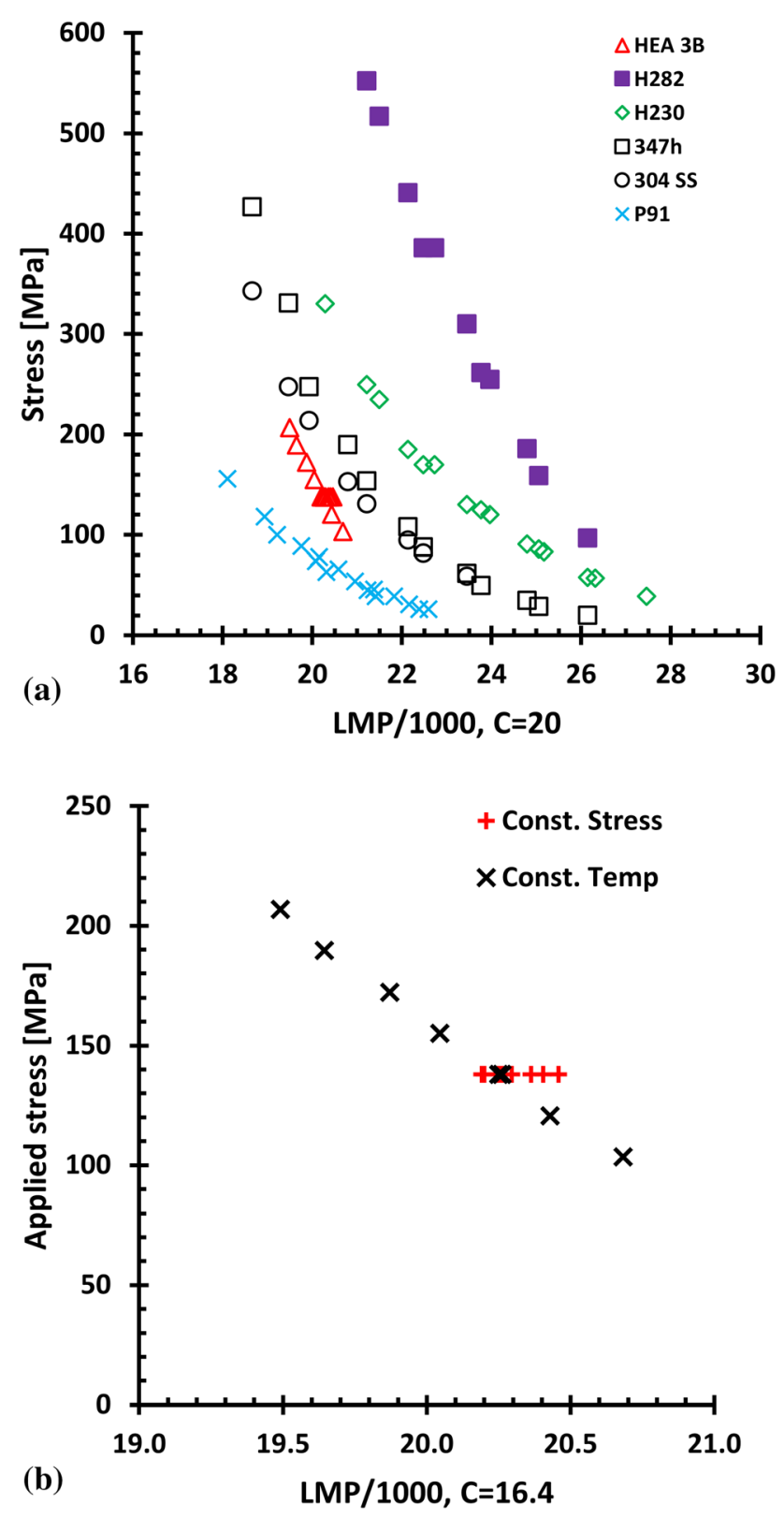

Fig. 7 Larson-Miller parameter (LMP) plot for a variety of alloys. a) With $\mathrm{C}=20$, b) $\mathrm{C}=16.4$

backbone of the power generation industry for heat-resistant alloys, and as a result, careful comparison is needed to evaluate the potential for HEA use as structural materials.

4.2.2 Activation Energy. It is well known steady-state creep rates (where they exist, i.e., ferritic-martensitic steels) follow an Arrhenius (exponential) relationship, as shown in Eq. 3.

$\dot{\epsilon}_{s s}=A \cdot \sigma^{n} \cdot \exp \left(\frac{-Q}{R} \cdot \frac{1}{T}\right)$

In Eq. 3, $\dot{\epsilon}_{S S}$ is the steady-state creep rate, $A$ and $n$ are constants, $Q$ is the activation energy, $R$ is the gas constant, and $T$ is temperature.

Using the minimum creep rates from Table 2, the apparent activation energy for creep in CoCrFeNiMn can be calculated.
Using a regression analysis on the MCR as a function of inverse temperature, an apparent activation energy of $394 \mathrm{~kJ} / \mathrm{mol}$ was calculated.

An apparent activation energy of $394 \mathrm{~kJ} / \mathrm{mol}$ is comparable to $347 / 347 \mathrm{H}$ austenitic stainless steel. Pilloni et al. (Ref 56) reported an apparent activation energy of 441 to $462 \mathrm{~kJ} / \mathrm{mol}$ for alloy 347 at 127 and $196 \mathrm{MPa}$ stress levels, respectively. Park et al. (Ref 57) also reported an apparent activation energy of 450 to $485 \mathrm{~kJ} / \mathrm{mol}$ from 120 to $250 \mathrm{MPa}$ for alloy 347. Park et al. (Ref 36) noted that $\sim 450 \mathrm{~kJ} / \mathrm{mol}$ is much higher than the lattice diffusion in the austenitic Fe matrix $(270 \mathrm{~kJ} / \mathrm{mol})$. Park et al. (Ref 36) attributed this increase in activation energy to strengthening particles such as carbides and other precipitates found along the grain boundaries in the commercial alloy. Figure 7(a) shows a comparison of creep life for $\mathrm{CoCrFeNiMn}$ to $347 / 347 \mathrm{H}$.

While unpublished at the time of preparation of this manuscript, both Jo et al. (Ref 58) and Rozman et al. (Ref 59) presented creep results on CoCrFeNiMn alloy at the annual TMS meeting in 2019 and independently measured an apparent activation energy near $394 \mathrm{~kJ} / \mathrm{mol}$. Both Rozman et al. and Jo et al. used tensile specimens with diameters $>4 \mathrm{~mm}$. Jo et al. measured extension from protrusions in the gage section, while Rozman et al. measured extension from notches on the specimen shoulder. For other publications, He et al. (Ref 19) reported an apparent activation energy of $333 \mathrm{~kJ} / \mathrm{mol}$ under slow strain rate testing of $\mathrm{CoCrNiFeMn}$ using dogbone-shaped tensile specimens $4 \mathrm{~mm}$ by $1.5 \mathrm{~mm}$ in cross-sectional area. He et al. also used strain rate jump tests to limit the number of samples needed. Cao et al. (Ref 24) measured an apparent activation energy of $385 \mathrm{~kJ} / \mathrm{mol}$ for $\mathrm{Al}_{0.15} \mathrm{CoCrNiFe}$ alloy, using stress relaxation tests with specimen diameter of $5 \mathrm{~mm}$. These authors noted their alloy was FCC with higher $\mathrm{Al}$ contents transforming the HEA crystal structure from FCC to BCC. The apparent activation energy reported in this manuscript agrees with studies on same or similar alloys.

In addition to the magnitude of the apparent activation energy for creep being comparable to austenitic stainless steels, the apparent activation energy for creep is above lattice diffusion of each element in the HEA. Tsai et al. (Ref 60) reported activation energies of $293 \mathrm{~kJ} / \mathrm{mol}$ for $\mathrm{Cr}, 288 \mathrm{~kJ} / \mathrm{mol}$ for $\mathrm{Mn}, 310 \mathrm{~kJ} / \mathrm{mol}$ for $\mathrm{Fe}, 307 \mathrm{~kJ} / \mathrm{mol}$ for $\mathrm{Co}$, and $318 \mathrm{~kJ} / \mathrm{mol}$ for Ni for self-diffusion in $\mathrm{NiCoFeCrMn}$. Vaidya et al. (Ref 61) published results in agreement with these activation energies. An apparent activation energy in line with lattice diffusion would suggest creep is modulated by dislocation climb as climb is rate limited by vacancy diffusion. An apparent activation energy above that of self-diffusion suggests there are additional obstacles in the matrix that hinder dislocation motion (Ref 57).

4.2.3 Creep Exponent. Utilizing the MCR at constant temperature, the stress exponent for creep of $\mathrm{CoCrFeNiMn}$ was calculated using regression analysis of the applied creep stress and MCR, see Eq. 3. A stress exponent for creep at $600{ }^{\circ} \mathrm{C}$ of 6.2 was calculated. When the value of $n$ lies between 1 and 2, diffusion-dominated creep behavior is the predominant deformation mechanism (Ref 62-64). When $n$ is between 3 and 7, dislocation creep predominates where dislocations glide, crossslip and climb are operative dislocation mechanisms (Ref 65). With a stress exponent measured at 6.2, dislocation creep is the most probable creep mechanism and that is to be expected in an alloy of this nature.

As noted in introduction, nano-indentation testing yields hard to interpret results. For comparison, Xu et al. (Ref 45) 
reported a creep exponent of 17 to 27 at room temperature in CoCrFeNiMn while Lee et al. (Ref 13) reported a stress exponent between 1 and 3 at room temperature also for CoCrFeNiMn. Furthermore, results from Chen et al. (Ref 39) report a creep exponent of $84-97$ at $200{ }^{\circ} \mathrm{C}$ for a $\mathrm{BCC}$ $\mathrm{Al}_{0.5} \mathrm{CoCrCuFeNi}$ HEA using nano-indentation. Cao et al. (Ref 31) tested full-size samples and found a stress exponent between 5 and 6 , which is in agreement with this research even though they tested a HEA with 0.15 at. $\% \mathrm{Al}$ in $\mathrm{CoCrFeNi}$ alloy using stress relaxation. For the 0.15 at.\% Al-containing alloy, XRD showed no $\mathrm{BCC}$ phase. For the $\mathrm{Al}_{0.6} \mathrm{CoCrFeNi}$ alloy which was BCC/FCC, the stress exponent was higher, i.e., from 8 to 10 . He et al. (Ref 66) reported a stress exponent of 2 at low stresses and 5 for stresses exceeding $100 \mathrm{MPa}$ on a CoCrFeNiMn alloy, where testing was once again done with full size samples with gage dimensions of $4 \mathrm{~mm} \times 1.3 \mathrm{~mm}$. When this research is compared to similar size-scale experiments, a stress exponent of 6.2 is in agreement with other published creep exponents for this general class of HEAs.

4.2.4 Monkman-Grant Relationship. Monkman and Grant (Ref 67) found an empirical relationship between creep rupture time and minimum creep rate, which when multiplied together are observed to be roughly constant. For $\mathrm{CoCrFe}$ NiMn, the Monkman-Grant relationship is observed both for creep tests conducted at constant stress with varying temperature and those conducted at constant temperature with varying stress, as shown in Fig. 8(a).

Much of the initial microstructure showed voids around the incoherent NiMnY phase, as shown in Fig. 2(b). These voids were maintained throughout the creep life (Fig. 9a and b) and may act as crack initiators, thereby decreasing overall creep performance in terms of its life. For materials where cavitation failure occurs, the creep damage tolerance factor $(\lambda)$ may discern how the material reacts to voids. The value of $\lambda$ is a modification to Monkman-Grant factor, see Eq. 4. The value of $\lambda$ is plotted in Fig. 8(b) as a function of time to failure.

$\lambda=\frac{\varepsilon_{r}}{\dot{\varepsilon}_{\min } \cdot t_{r}}$

In Eq. $4, \lambda$ is the creep damage tolerance factor, $\varepsilon_{r}$ is the elongation at rupture, $\dot{\varepsilon}_{\text {min }}$ is the minimum creep rate, and $t_{r}$ is the time at rupture.

For materials with $\lambda=1$, creep behavior is brittle without any significant plastic deformation (Ref 68). For $1<\lambda<2.5$, materials show low rupture strain and damage is accumulated by grain boundary cavity growth (Ref 69). Also, for $\lambda>2$, necking occurs, and for $\lambda>5$ microstructural features tend to coarsen and dislocation annihilation is the primary damage mechanism (Ref 69). The minimum value for $\lambda$ was 2.9 , corresponding to the test at $600{ }^{\circ} \mathrm{C}$ and $190 \mathrm{MPa}$, which lasted $315 \mathrm{~h}$ with elongation of $40.6 \%$. As the value of $\lambda>2.5$ and elongations were $>30 \%$, grain boundary void growth is not of concern.

\subsection{Deformation Discussion}

4.3.1 Microstructural Observations. While statistically significant quantification of size, phase fraction, and aspect ratio of precipitated $\sigma$ was not done, preliminary observations show that at lower stresses, i.e., $100 \mathrm{MPa}$ (Fig. 9a, with $\sigma$ overlaid in red), $\sigma$ is relatively larger and infrequent compared to tests at higher stresses, i.e., $170 \mathrm{MPa}$ (Fig. 9b, with $\sigma$
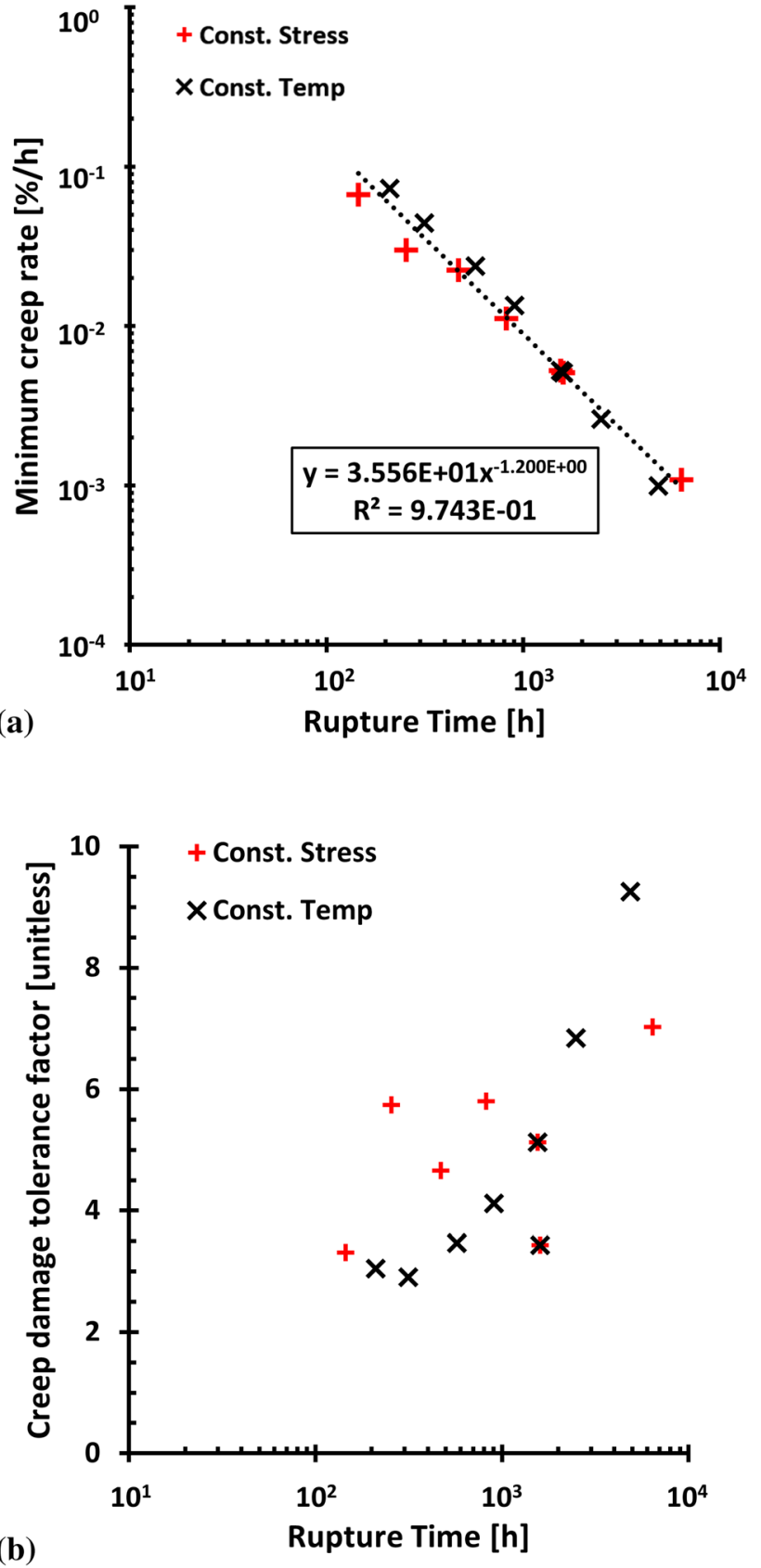

Fig. 8 Relationship between minimum creep rate (MCR) and time to rupture. (a) Monkman-Grant relationship and (b) creep damage tolerance factor $(\lambda)$

overlaid in red). For both stresses, from a macroscopic point of view, $\sigma$ tended to form a necklace structure around the matrix grains. In addition to the coarsening, cavitation damage is associated with these phases, suggesting they may act as crack initiators. The $\sigma$ phase (identified by size, $<5 \mu \mathrm{m}$ and brighter contrast than the matrix) is found at the pit of the ductile cup and cone fracture (Fig. 9c and d), suggesting they may initiate micro-void coalescence. However, it is difficult to discern voids associated with $\sigma$ phase development from those of the original voids due to the Y-rich phases from micro-void coalescence. No large 5-20- $\mu \mathrm{m}$, bright (in backscatter mode on the SEM) precipitates were found on the fracture surfaces. 

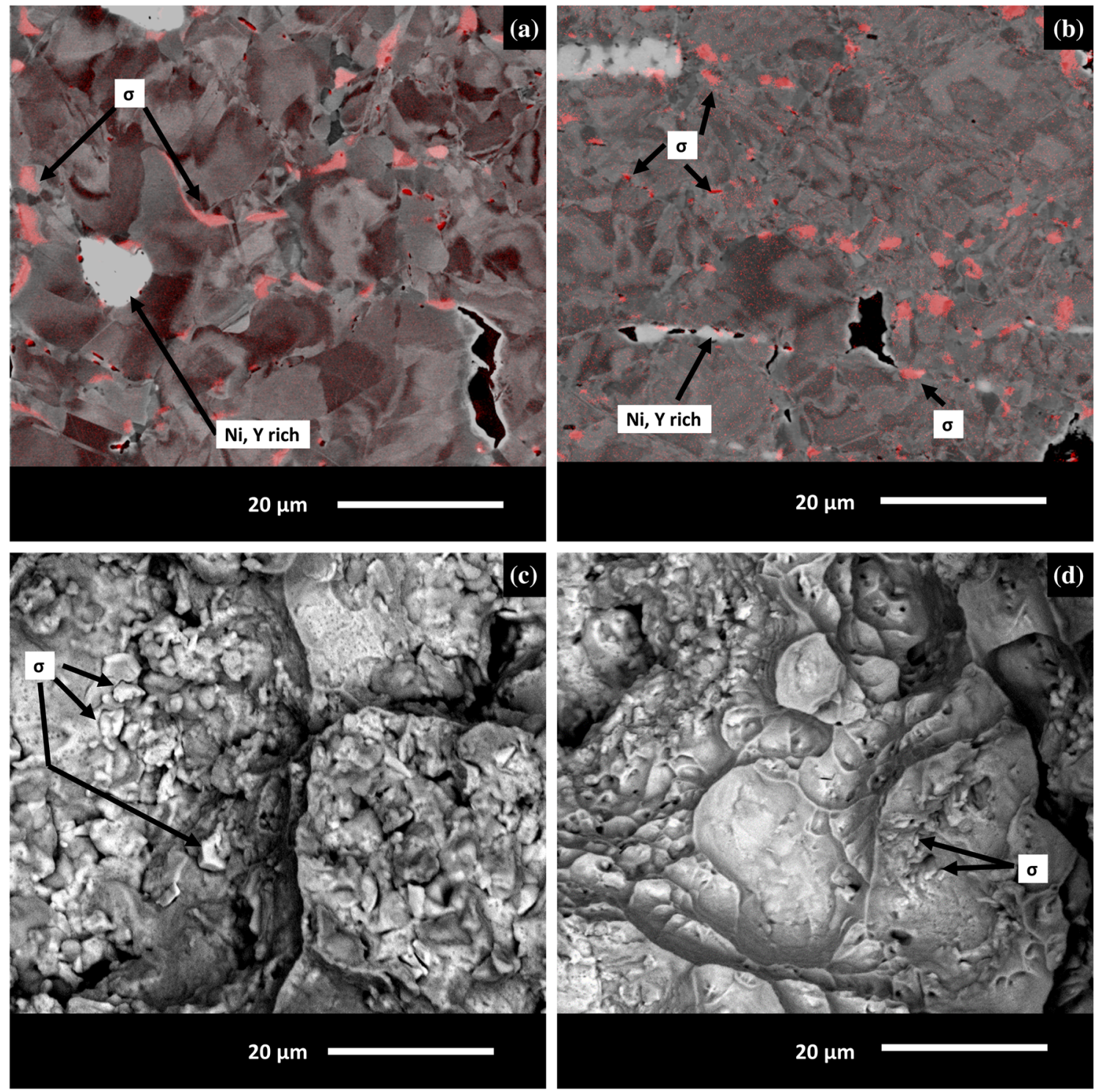

Fig. 9 Backscatter SEM micrographs showing (a) microstructure from specimen creep tested at $600{ }^{\circ} \mathrm{C}$ at $100 \mathrm{MPa}$ with $\mathrm{Cr}$ map overlaid in red, (b) microstructure from specimen creep tested at $600{ }^{\circ} \mathrm{C}$ at $170 \mathrm{MPa}$ with $\mathrm{Cr}$ map overlaid in red, (c) fracture surface from (a), and (d) fracture surface from (b)

Voids may have formed to allow for lattice mismatch as the $\sigma$ phase grows. However, $\sigma$ phase is found at the base of many dimples (Fig. 9c and d) suggesting it is, in part, associated with micro-void coalescence.

CoCrFeNiMn alloys are reported to have high fracture toughness, $\sim 220 \mathrm{MPa} \sqrt{\mathrm{m}}$ (Ref 70 ) which is higher than maraging steel (Ref 71). Fracture toughness is the ability of materials to resist crack extension. As such, the high fracture toughness of the CoCrFeNiMn alloy may make it less susceptible to cavitation damage from the evolving/growing $\sigma$ phase. This may explain why this alloy has large cavities which resist linking and rapid failure, unlike other alloys which show intergranular failure after short times (Ref 72).
4.3.2 Microstructural Hardness. Hardness can give an idea on the effect of precipitates on deformation. Hardness measurements were taken from cross sections of the initial homogenized casting, from the gage section from the room temperature tensile specimen and from the grip/gage regions of specimen crept at $575^{\circ} \mathrm{C} / 140 \mathrm{MPa}, 600^{\circ} \mathrm{C} / 100 \mathrm{MPa}$ and $600{ }^{\circ} \mathrm{C} / 170 \mathrm{MPa}$ (see Fig. 10).

By measuring the hardness in the gage section of the room temperature tensile specimen, the effect of strain hardening may be explored. Strain hardening had the effect of increasing Vickers hardness from $130 \mathrm{~kg} / \mathrm{mm}^{2}$ to $244 \mathrm{~kg} / \mathrm{mm}^{2}$. The grip section of the crept samples should be relatively stress-free, such that any increase in hardness would originate from 


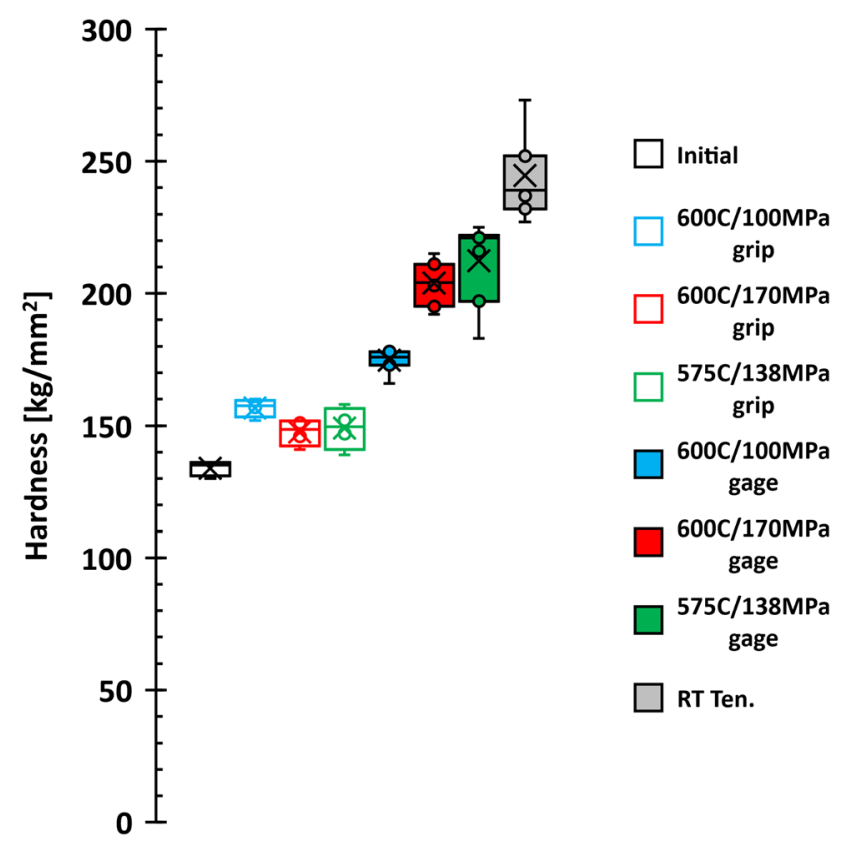

Fig. 10 Vickers hardness measurement of various specimens at different exposure conditions

microstructural evolution opposed to strain hardening. An increase from $130 \mathrm{~kg} / \mathrm{mm}^{2}$ to an average hardness of $150 \mathrm{~kg} /$ $\mathrm{mm}^{2}$ was noted in the grip sections of the creep samples. Some limited precipitation of $\sigma$ phase was noted in the grip section which may explain a portion of the hardness increase.

By measuring the hardness of the gage sections from the creep specimens and comparing to the initial hardness, and from strain hardening in room temperature tensile specimen, the relative effect of $\sigma$ phase precipitation and growth can be assessed. An increase in hardness from $130 \mathrm{~kg} / \mathrm{mm}^{2}$ to $174 \mathrm{~kg} /$ $\mathrm{mm}^{2}$ was noted for the specimen crept at $600{ }^{\circ} \mathrm{C}$ and $100 \mathrm{MPa}$. This specimen had large $\sigma$ phase precipitates, see Fig. 9(a). An increase in hardness from $130 \mathrm{~kg} / \mathrm{mm}^{2}$ to $204 \mathrm{~kg} / \mathrm{mm}^{2}$ was noted for the specimen crept at $600{ }^{\circ} \mathrm{C}$ and $170 \mathrm{MPa}$. For this specimen, small $\sigma$ phase precipitates were found along the grain boundaries, see Fig. 9(b). Both specimens possessed lower Vickers hardness than the room temperature tensile specimen at $244 \mathrm{~kg} / \mathrm{mm}^{2}$. However, the Vickers hardness in the crept gage sections was higher than the Vickers hardness of the initial microstructure, i.e., $130 \mathrm{~kg} / \mathrm{mm}^{2}$ and also in the grip section, $150 \mathrm{~kg} / \mathrm{mm}^{2}$. This may suggest $\sigma$ phase offers some strength increase in addition to strain hardening due to creep (while much less than was observed in the room temperature gage section).

The elongation of the specimen creep tested at $103 \mathrm{MPa}$ at $600{ }^{\circ} \mathrm{C}$ was $\sim 45 \%$, while the specimen at $170 \mathrm{MPa}$ at $600{ }^{\circ} \mathrm{C}$ was $52 \%$, or about $15 \%$ higher. It should be noted from the tensile tests this alloy strain hardens significantly (Ref 17). While the specimen at $103 \mathrm{MPa}$ at $600{ }^{\circ} \mathrm{C}$ had larger (and perhaps) 'overaged' $\sigma$ precipitates (Fig. 9a) relative to the smaller $\sigma$ precipitates lining grain boundaries (Fig. 9b), it cannot be concluded from this information alone that size of the $\sigma$ precipitates had any influence on the strength (hardness) of the alloy.
4.3.3 Dislocation Observations. Limited TEM investigations on the microstructure and dislocation structure were conducted. Broad overview of a region of the microstructure in the TEM shows dislocation free $\sigma$ phases (Fig. 11a), dislocation impingement at the grain boundaries and at carbides (Fig. 11a and d), twinning (Fig. 11c), and stacking faults (not shown). Evidence of persistent slip bands (PSB) was found in the specimen crept at $207 \mathrm{MPa}$ at $600{ }^{\circ} \mathrm{C}$, as shown in Fig. $11(\mathrm{c})$. At $600{ }^{\circ} \mathrm{C}$, the alloy had a yield stress of $184 \mathrm{MPa}$, so evidence of PSB is not surprising for an FCC alloy. Some evidence of dislocation pinning is found for the specimen crept at $650{ }^{\circ} \mathrm{C}$ at $137.9 \mathrm{MPa}$ (Fig. 11c) and at $600{ }^{\circ} \mathrm{C}$ at $207 \mathrm{MPa}$ (Fig. 11b), where dislocations appear to have periodic 'dots' associated with them. Furthermore, the general dislocation structure, i.e., the density of dislocations and the tangled nature of the interior of the grains, is less so at higher temperatures (see Fig. 11b relative to Fig. 11c), which is typical of FCC materials.

With the increase in hardness in the gage section (i.e., matrix strength), TEM was used to see if the increase in hardness arose from strain hardening mechanisms or interactions with $\sigma$. Preliminary observations show that at higher stresses, typical FCC plastic deformation structures are observed, including PSBs (Fig. 11c). This may suggest an increase in hardness (strength) at higher stresses originates from strain hardening. At lower stresses, general dislocation interactions and impingement at grain boundaries are observed and would suggest the boundary and the phases contained therein (i.e., $\mathrm{Cr}_{23} \mathrm{C}_{6}$ or $\sigma$ ) are locally strengthening the microstructure (see Fig. 11d). Further TEM investigations will be needed to more thoroughly analyze the interactions between $\sigma$ phase and the other microstructural features in order to unambiguously assess their contribution to alloy deformation behavior.

\section{Summary}

A FCC CoCrFeNiMn HEA of approximate equiatomic composition (with some minor chemical additions for strengthening) was tested in an axial creep tensile configuration at elevated temperature. The test specimens failed in a ductile manner with the creep life assessed using the Larson-Miller parameter. Comparison with other typical power plant alloys, P91 ferritic-martensitic steel and $347 / 347 \mathrm{H}$ austenitic stainless steel, showed the alloy was more creep resistant compared to P91 but less creep resistant compared to $347 \mathrm{H}$. Typical creep behavior was observed with MCR decreasing as temperature and/or stress was lowered. Greater than $80 \%$ of the alloy's creep lifetime was spent in a transition region between secondary and tertiary creep.

The initial microstructure prior to elevated temperature creep testing was single phase at the exception of some large Ni- and Y-rich precipitates which were incoherent with the matrix. The final microstructure showed primary $\mathrm{Cr}$ segregation, with other elements segregating as well but to a lesser degree, that facilitated the formation of $\sigma$ phase. Of note was evidence of cavitation damage surrounding the $\sigma$ phase when examining the creep fracture surfaces. At higher stresses, the $\sigma$ phase precipitated as a necklace structure along the grain 

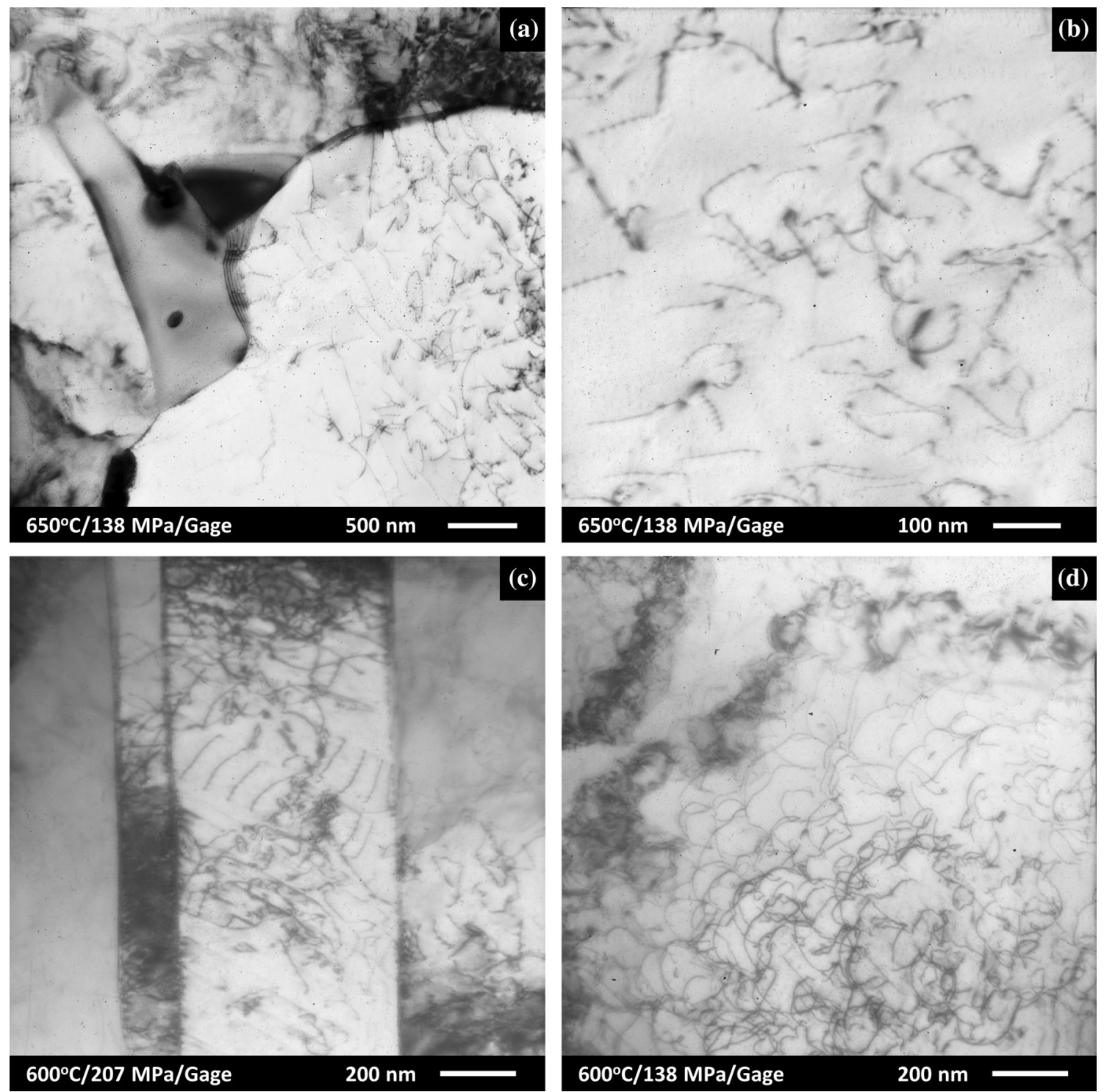

Fig. 11 TEM micrographs of CoCrFeNiMn in the gage section of creep specimen. (a) $650{ }^{\circ} \mathrm{C}$ and $137.9 \mathrm{MPa}$, (b) $650{ }^{\circ} \mathrm{C}$ and $137.9 \mathrm{MPa}$, (c) $600{ }^{\circ} \mathrm{C}$ and $207 \mathrm{MPa}$, and (d) $600{ }^{\circ} \mathrm{C}$ at $137.9 \mathrm{MPa}$

boundaries. At lower stresses, $\sigma$ phase was found as relatively large $(\sim 5 \mu \mathrm{m}$ diameter) precipitates. The $\sigma$ phase measured in the final microstructure was significantly larger than that reported elsewhere. Utilization of the creep damage tolerance factor showed that while the alloy cavitated due to $\sigma$ phase, fracture by micro-void initiation, growth, and coalescence did not occur until very late in tertiary creep.

Analyzing the MCR as a function of stress produced a creep exponent of 6.2, consistent with dislocation modulated creep. An apparent creep activation energy of $394 \mathrm{~kJ} / \mathrm{mol}$ was calculated, which is higher than matrix self-diffusion, suggesting that some matrix hardening occurred during creep. Microstructure observation and hardness measurements suggest $\sigma$ phase may be responsible, but additional analysis is needed to confirm. Post-mortem Vickers hardness measurements verified hardening of the matrix (as measured at room temperature). However, the approach used is insufficient in understanding whether the increase in strength during creep arises from strain hardening or $\sigma$ phase acting as a hardening feature.

This research was a first attempt at evaluating the performance of single-phase FCC HEAs as a structural material for energy applications. Performance, while less than desired, was consistent with FCC materials. More importantly, it provided insight as to deformation behavior, especially in creep where the microstructure evolution into $\sigma$ phase was an important observation. This result highlighted the necessity to look more closely at HEA manufacture, especially the homogenization cycle when using ThermoCalc (not designed for HEA-type materials) to gauge cycle temperature and time. Subsequent work has been performed on HEAs produced after this first attempt where improvements in creep life have been achieved. More will be reported on this aspect in later publications. 


\section{Acknowledgments}

This work was performed in support of the US Department of Energy's Fossil Energy Crosscutting Technology Research Program. The Research was executed through the NETL Research and Innovation Center's Advanced Alloy Development Field Work Proposal. Research performed by Leidos Research Support Team (LRST) staff was conducted under the RSS contract 89243318CFE000003.

\section{Disclaimer}

This work was funded by the Department of Energy, National Energy Technology Laboratory, an agency of the US Government, through a support contract with LRST. Neither the US Government nor any agency thereof, nor any of their employees, nor LRST, nor any of their employees, makes any warranty, expressed or implied, or assumes any legal liability or responsibility for the accuracy, completeness, or usefulness of any information, apparatus, product, or process disclosed, or represents that its use would not infringe privately owned rights. Reference herein to any specific commercial product, process, or service by trade name, trademark, manufacturer, or otherwise, does not necessarily constitute or imply its endorsement, recommendation, or favoring by the US Government or any agency thereof. The views and opinions of authors expressed herein do not necessarily state or reflect those of the US Government or any agency thereof.

\section{Calculations}

The following plots show the relationships and fits to derive various parameters as noted in the main text.

Figure 12 shows the relationship between inverse temperature and logarithm of rupture time used to calculate the Larson-Miller C-value. The constant $\mathrm{C}$ is the absolute value of the intercept of the linear fit, 16.35 .

Figure 13 shows the relationship between inverse temperature and MCR to calculate the activation energy. The

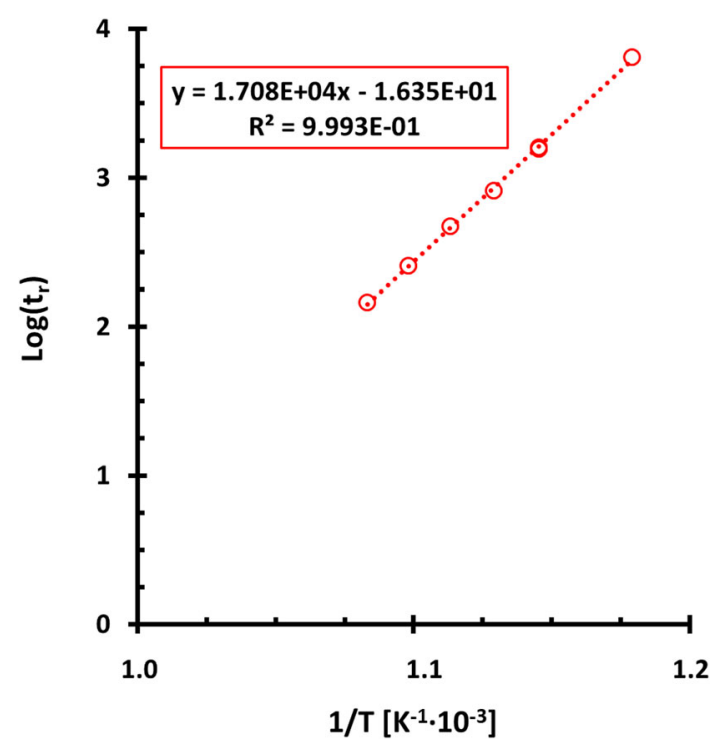

Fig. 12 Determination of LMP-C value

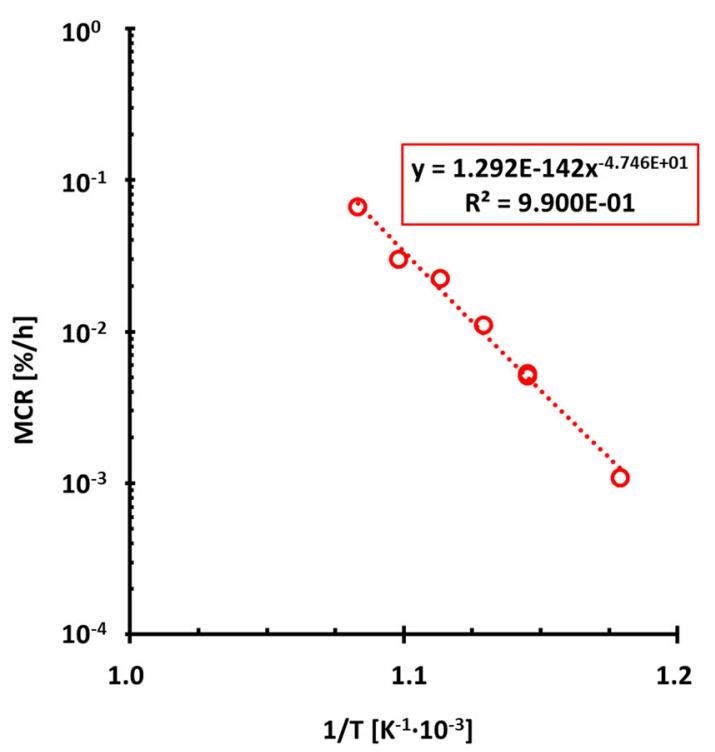

Fig. 13 Determination of the activation energy for creep calculation

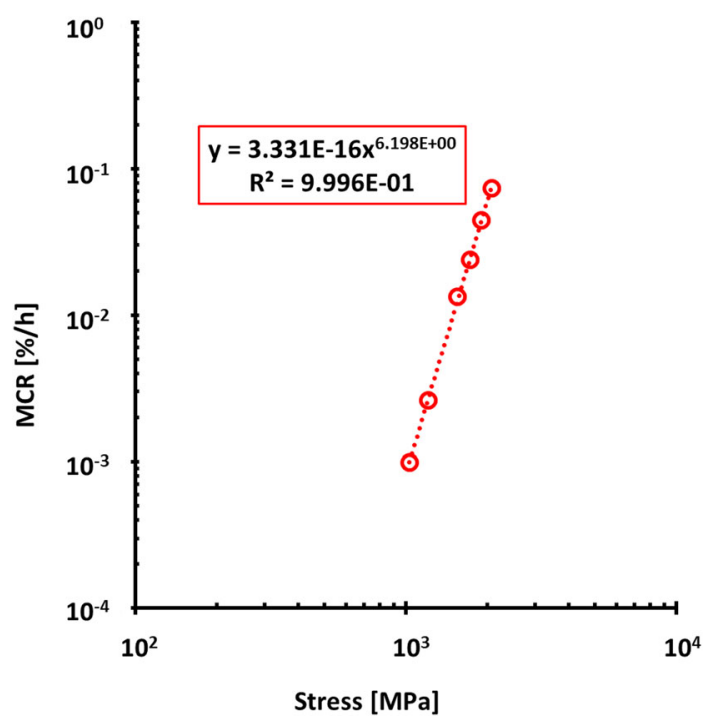

Fig. 14 Determination of the creep exponent calculation

activation energy is derived from the exponent in the powerlaw fit. $-47.46=-Q / 8.314 \quad[\mathrm{~J} / \mathrm{K} / \mathrm{mol}] \quad * \quad 1 / T \quad[\mathrm{~K}]$; $Q=394 \mathrm{~kJ} / \mathrm{mol}$.

Figure 14 shows the relationship between stress and MCR to calculate the creep exponent. The stress exponent is the exponent value of the power-law fit, 6.198.

\section{References}

1. J.W. Qiao, M.L. Bao, Y.J. Zhao, H.J. Yang, Y.C. Wu, Y. Zhang et al., Rare-Earth High Entropy Alloys with Hexagonal Close-Packed Structure, J. Appl. Phys., 2018, 124, p 195101

2. M.C. Gao, P.D. Jablonski, J.A. Hawk, D.E, Alman. High-Entropy Alloys: Formation and Properties, in ASME 2018 Symposium on 
Elevated Temperature Application of Materials for Fossil, Nuclear, and Petrochemical Industries (2018)

3. H. Jiang, K. Han, X. Gao, Y. Lu, Z. Cao, M.C. Gao et al., A New Strategy to Design Eutectic High-Entropy Alloys Using Simple Mixture Method, Mater. Des., 2018, 142, p 101-105

4. R. Feng, M.C. Gao, C. Zhang, W. Guo, J.D. Poplawsky, F. Zhang et al., Phase Stability and Transformation in a Light-Weight High-Entropy Alloy, Acta Mater., 2018, 146, p 280-293

5. T. Zuo, M.C. Gao, L. Ouyang, X. Yang, Y. Cheng, R. Feng et al., Tailoring Magnetic Behavior of $\mathrm{CoFeMnNiX}(\mathrm{X}=\mathrm{Al}, \mathrm{Cr}, \mathrm{Ga}, \mathrm{Sn}) \mathrm{High}$ Entropy Alloys by Metal Doping, Acta Mater., 2017, 130, p 10-18

6. M.C. Gao, C. Zhang, P. Gao, F. Zhang, L.Z. Ouyang, M. Widom et al., Thermodynamics of Concentrated Solid Solution Alloys, Curr. Opin. Solid State Mater. Sci., 2017, 21, p 238-251

7. M.C. Gao, P. Gao, J.A. Hawk, L.Z. Ouyang, D.E. Alman, and M. Widom, Computational Modeling of High-Entropy Alloys: Structures: Thermodynamics and Elasticity, J. Mater. Res., 2017, 32, p 3627-3641

8. H.W. Yao, J.W. Qiao, M.C. Gao, J.A. Hawk, S.G. Ma, H.F. Zhou et al., NbTaV-(Ti, W) Refractory High-Entropy Alloys: Experiments and Modeling, Mater. Sci. Eng. A, 2016, 674, p 203-211

9. H. Yao, J.-W. Qiao, M.C. Gao, J.A. Hawk, S.-G. Ma, and H. Zhou, Correction to Yao, H.; Qiao, J.-W.; Gao, M.C.; Hawk, J.A.; Ma, S.-G.; Zhou, H. MoNbTaV Medium-Entropy Alloy, Entropy, 2016, 18, p 189

10. H. Yao, J.-W. Qiao, M.C. Gao, J.A. Hawk, S.-G. Ma, and H. Zhou, MoNbTaV Medium-Entropy Alloy, Entropy, 2016, 18, p 189

11. M.C. Gao, B. Zhang, S.M. Guo, J.W. Qiao, and J.A. Hawk, HighEntropy Alloys in Hexagonal Close-Packed Structure, Metall. Mater. Trans. A, 2016, 47, p 3322-3332

12. S. Antonov, M. Detrois, and S. Tin, Design of Novel PrecipitateStrengthened Al-Co-Cr-Fe-Nb-Ni High-Entropy Superalloys, Metall. Mater. Trans. A, 2018, 49, p 305-320

13. M. Detrois, S. Antonov, and S. Tin, Phase Stability and Thermodynamic Database Validation in a Set of Non-equiatomic Al-Co-Cr-FeNb-Ni High-Entropy Alloys, Intermetallics, 2019, 104, p 103-112

14. M.C. Gao, C.S. Carney, Ö.N. Doğan, P.D. Jablonksi, J.A. Hawk, and D.E. Alman, Design of Refractory High-Entropy Alloys, JOM, 2015, 67, p 2653-2669

15. R. Feng, M.C. Gao, C. Lee, M. Mathes, T. Zuo, S. Chen, J.A. Hawk, Y. Zhang, and P.K. Liaw, Design of Light-Weight High-Entropy Alloys, Entropy, 2016, 18(9), p 333. https://doi.org/10.3390/e18090333

16. P.D. Jablonski, J.J. Licavoli, M.C. Gao, and J.A. Hawk, Manufacturing of High Entropy Alloys, JOM, 2015, 67, p 2278-2287

17. J.J. Licavoli, M.C. Gao, J.S. Sears, P.D. Jablonski, and J.A. Hawk, Microstructure and Mechanical Behavior of High-Entropy Alloys, $J$. Mater. Eng. Perform., 2015, 24, p 3685-3698

18. M. Detrois, S. Antonov, S. Tin, P.D. Jablonski, and J.A. Hawk, Hot Deformation Behavior and Flow Stress Modeling of a Ni-Based Superalloy, Mater. Charact., 2019, 157, p 109915

19. D. Li, M.C. Gao, J.A. Hawk, and Y. Zhang, Annealing Effect for the A10.3CoCrFeNi High-Entropy Alloy Fibers, J. Alloys Compd., 2019, 778, p 23-29

20. M. Chen, X.H. Shi, H. Yang, P.K. Liaw, M.C. Gao, J.A. Hawk et al., Wear Behavior of A10.6CoCrFeNi High-Entropy Alloys: Effect of Environments, J. Mater. Res., 2018, 33, p 3310-3320

21. H.W. Yao, J.W. Qiao, J.A. Hawk, H.F. Zhou, M.W. Chen, and M.C. Gao, Mechanical Properties of Refractory High-Entropy Alloys: Experiments and Modeling, J. Alloys Compd., 2017, 696, p 1139-1150

22. M. Detrois, P.D. Jablonski, S. Antonov, S. Li, Y. Ren, S. Tin et al., Design and Thermomechanical Properties of a $\gamma^{\prime}$ Percipitate-Strengthened Ni-Based Superalloy with High Entropy $\gamma$ Matrix, J. Alloys Compd., 2019, 792, p 550-560

23. G.R. Holcomb, J. Tylczak, and C. Carney, Oxidation of CoCrFeMnNi High Entropy Alloys, JOM, 2015, 67, p 2326-2339

24. Ö.N. Doğan, B.C. Nielsen, and J.A. Hawk, Elevated-Temperature Corrosion of $\mathrm{CoCrCuFeNiAl0.5Bx}$ High-Entropy Alloys in Simulated Syngas Containing H2S, Oxid. Met., 2013, 80, p 177-190

25. A.A. Rodriguez, J.H. Tylczak, M.C. Gao, P.D. Jablonski, M. Detrois, M. Ziomek-Moroz, et al. Effect of Molybdenum on the Corrosion Behavior of High-Entropy Alloys $\mathrm{CoCrFeNi} 2$ and $\mathrm{CoCrFeNi2Mo0.25}$ under Sodium Chloride Aqueous Conditions. Adv. Mater. Sci. Eng. 2018;2018:11

26. A. Rodriguez, J.H. Tylczak, and M. Ziomek-Moroz, Corrosion Behavior of CoCrFeMnNi High-Entropy Alloys (HEAs) Under Aqueous Acidic Conditions, ECS Trans., 2017, 77, p 741-752
27. A. Di Gianfrancesco, S.T. Vipraio, and D. Venditti, Long Term Microstructural Evolution of 9-12\%Cr Steel Grades for Steam Power Generation Plants, Procedia Eng., 2013, 55, p 27-35

28. W. Xia, X. Zhao, L. Yue, and Z. Zhang, Microstructural Evolution and Creep Mechanisms in Ni-Based Single Crystal Superalloys: A Review, J. Alloys Compd., 2020, 819, p 152954

29. E.J. Pickering, R. Muñoz-Moreno, H.J. Stone, and N.G. Jones, Precipitation in the Equiatomic High-Entropy Alloy CrMnFeCoNi, Scr. Mater., 2016, 113, p 106-109

30. G. Laplanche, P. Gadaud, O. Horst, F. Otto, G. Eggeler, and E.P. George, Temperature Dependencies of the Elastic Moduli and Thermal Expansion Coefficient of an Equiatomic, Single-Phase CoCrFeMnNi High-Entropy Alloy, J. Alloys Compd., 2015, 623, p 348-353

31. T. Cao, J. Shang, J. Zhao, C. Cheng, R. Wang, and H. Wang, The Influence of $\mathrm{Al}$ Elements on the Structure and the Creep Behavior of AlxCoCrFeNi High Entropy Alloys, Mater. Lett., 2016, 164, p 344347

32. F. Otto, A. Dlouhý, K.G. Pradeep, M. Kuběnová, D. Raabe, G. Eggeler et al., Decomposition of the Single-Phase High-Entropy Alloy $\mathrm{CrMnFeCoNi}$ After Prolonged Anneals at Intermediate Temperatures, Acta Mater., 2016, 112, p 40-52

33. S.I. Hong, J. Moon, S.K. Hong, and H.S. Kim, Thermally Activated Deformation and the Rate Controlling Mechanism in CoCrFeMnNi High Entropy Alloy, Mater. Sci. Eng. A, 2017, 682, p 569-576

34. Y.B. Kang, S.H. Shim, K.H. Lee, and S.I. Hong, Dislocation Creep Behavior of CoCrFeMnNi High Entropy Alloy at Intermediate Temperatures, Mater. Res. Lett., 2018, 6, p 689-695

35. C. Cao, J. Fu, T. Tong, Y. Hao, P. Gu, H. Hao et al., IntermediateTemperature Creep Deformation and Microstructural Evolution of an Equiatomic FCC-Structured CoCrFeNiMn High-Entropy Alloy, Entropy, 2018, 20, p 960

36. D.-H. Lee, M.-Y. Seok, Y. Zhao, I.-C. Choi, J. He, Z. Lu et al., Spherical Nanoindentation Creep Behavior of Nanocrystalline and Coarse-Grained CoCrFeMnNi High-Entropy Alloys, Acta Mater., 2016, 109, p 314-322

37. B. Wang, H. He, M. Naeem, S. Lan, S. Harjo, T. Kawasaki et al., Deformation of CoCrFeNi High Entropy Alloy at Large Strain, Scr. Mater, 2018, 155, p 54-57

38. T. Zhang, L. Xin, F. Wu, R. Zhao, J. Xiang, M. Chen et al., Microstructure and Mechanical Properties of FexCoCrNiMn HighEntropy Alloys, J. Mater. Sci. Technol., 2019, 35, p 2331-2335

39. S. Chen, W. Li, X. Xie, J. Brechtl, B. Chen, P. Li et al., Nanoscale Serration and Creep Characteristics of $\mathrm{Al} 0.5 \mathrm{CoCrCuFeNi}$ HighEntropy Alloys, J. Alloys Compd., 2018, 752, p 464-475

40. J. Dean, J. Campbell, G. Aldrich-Smith, and T.W. Clyne, A Critical Assessment of the "Stable Indenter Velocity" Method for Obtaining the Creep Stress Exponent from Indentation Data, Acta Mater., 2014, 80, p 56-66

41. J. Campbell, J. Dean, and T.W. Clyne, Limit Case Analysis of the "Stable Indenter Velocity" Method for Obtaining Creep Stress Exponents from Constant Load Indentation Creep Tests, Mech. TimeDepend. Mater., 2017, 21, p 31-43

42. P.D. Jablonski and J.A. Hawk, Homogenizing Advanced Alloys: Thermodynamic and Kinetic Simulations Followed by Experimental Results, J. Mater. Eng. Perform., 2017, 26, p 4-13

43. P.J.J. Hawk, Considerations for Homogenizing Alloys, in 8th International Symposium on Superalloy 718 and Derivatives, pp. 823-840 (2014)

44. P.D. Jablonski, J.A. Hawk, Thermodynamic and Kinetic Simulation and Experimental Results Homogenizing Advanced Alloys, in Conference Proceedings of 23rd IFHTSE Congress Advanced Thermal Processing IV. Savannah, GA2016, p. 10

45. M. Detrois, P.D. Jablonski, Trace Element Control in Binary Ni- $25 \mathrm{Cr}$ and Ternary Ni-30C0-30Cr Master Alloy Castings, in ed. by M.J.M. Krane RMW, S. Rudoler, A.J. Elliott, A. Pate. Proceeding of the Liquid Metal Processing \& Casting Conference (2017), pp. 75-84

46. International A. Standard Guide for Elemental Analysis by Wavelength Dispersive X-Ray Fluorescence Spectrometry. West Conshohocken, PA (2013)

47. International A. Standard Test Methods for Determination of Carbon, Sulfur, Nitrogen, and Oxygen in Steel, Iron, Nickel, and Cobalt Alloys by Various Combustion and Inert Gas Fusion Techniques. West Conshohocken, PA (2018) 
48. ASTM E139-11, Standard Test Methods for Conducting Creep, CreepRupture, and Stress-Rupture Tests of Metallic Materials. (ASTM International, West Conshohocken, PA, 2018)

49. F.R. Larson and J. Miller, A Time-Temperature Relationship for Rupture and Creep Stresses, Trans. ASME, 1952, 74, p 765-771

50. F. Otto, A. Dlouhý, C. Somsen, H. Bei, G. Eggeler, and E.P. George, The Influences of Temperature and Microstructure on the Tensile Properties of a CoCrFeMnNi High-Entropy Alloy, Acta Mater, 2013, 61, p 5743-5755

51. M.-Y. Kim, S.-M. Hong, K.-H. Lee, W.-S. Jung, Y.-S. Lee, Y.-K. Lee et al., Mechanism for Z-Phase Formation in 11CrMoVNbN Martensitic Heat-Resistant Steel, Mater. Charact., 2017, 129, p 40-45

52. A. Fedoseeva, I. Nikitin, N. Dudova, and R. Kaibyshev, Strain-Induced Z-Phase Formation in a 9\% Cr-3\% Co Martensitic Steel During Creep at Elevated Temperature, Mater. Sci. Eng. A, 2018, 724, p 29-36

53. High Temperature Characteristics of Stainless Steels: Designers' Handbook Series No. 9004, American Iron and Steel Institute, 2011. American Iron and Steel Institute; 2011

54. F.T. Furillo, S. Purushothaman, and J.K. Tien, Understanding the Larson-Miller Parameter, Scr. Metall., 1977, 11, p 493-496

55. K.A. Rozman, M.A. Carl, M. Kapoor, Ö.N. Doğan, J.A. Hawk, Creep Performance of Transient Liquid Phase Bonded Haynes 230 Alloy. Mater. Sci. Eng. A 2019:138477

56. G. Pilloni, E. Quadrini, and S. Spigarelli, Interpretation of the Role of Forest Dislocations and Precipitates in High-Temperature Creep in a Nb-Stabilised Austenitic Stainless Steel, Mater. Sci. Eng. A, 2000, 279, p 52-60

57. D.-B. Park, S.-M. Hong, K.-H. Lee, M.-Y. Huh, J.-Y. Suh, S.-C. Lee et al., High-Temperature Creep Behavior and Microstructural Evolution of an $18 \mathrm{Cr} 9 \mathrm{Ni} 3 \mathrm{CuNbVN}$ Austenitic Stainless Steel, Mater. Charact., 2014, 93, p 52-61

58. K.A. Rozman, M. Detrois, P. Jablonski, M. Gao, and J. Hawk, High Temperature Creep Behavior of Face Centered Cubic High Entropy Alloys. TMS2019, High Entropy Alloys VII: synthesis and mechanical properties (San Antonio, TX, USA, 2019)

59. K.A. Rozman, M. Detrois, P. Jablonski, M. Gao, and J. Hawk, Creep Performance of Single Phase FCC High Entropy Alloys, in TMS 2019 Annual (San Antonio, TX, 2019)
60. K.Y. Tsai, M.H. Tsai, and J.W. Yeh, Sluggish Diffusion in $\mathrm{Co}-\mathrm{Cr}-\mathrm{Fe}-$ Mn-Ni High-Entropy Alloys, Acta Mater, 2013, 61, p 4887-4897

61. M. Vaidya, K.G. Pradeep, B.S. Murty, G. Wilde, and S.V. Divinski, Bulk Tracer Diffusion in CoCrFeNi and CoCrFeMnNi High Entropy Alloys, Acta Mater., 2018, 146, p 211-224

62. F.R.N. Nabarro, Deformation of Crystals by the Motion of Single Lonsin Report of a Conference on the Strength of Solids. Physical Society. Bristol, U.K., (1948), pp. 75-90

63. R.L. Coble, A Model for Boundary Diffusion Controlled Creep in Polycrystalline Materials, J. Appl. Phys., 1963, 34, p 1679-1682

64. C. Herring, Diffusional Viscosity of a Polycrystalline Solid, J. Appl. Phys., 1950, 21, p 437-445

65. M.A. Meyers and K.K. Chawla, Mechanical Behavior of Materials, 2nd edn. (Cambridge University Press, Cambridge, 2009)

66. J.Y. He, C. Zhu, D.Q. Zhou, W.H. Liu, T.G. Nieh, and Z.P. Lu, Steady State Flow of the FeCoNiCrMn High Entropy Alloy at Elevated Temperatures, Intermetallics, 2014, 55, p 9-14

67. E.C. Monkman and N.J. Grant, An Empirical Relationship between Rupture Life and Minimum Creep Rate in Creep-Rupture Tests, Proc. ASTM., 1956, 56, p 593

68. M. Ashby and B. Dyson, Creep Damage Mechanics and Micromechanisms, Fracture, 1984, 84, p 3-30

69. A. Cocks and M. Ashby, Intergranular Fracture During Power-Law Creep Under Multiaxial Stresses, Metal Sci., 1980, 14, p 395-402

70. B. Gludovatz, A. Hohenwarter, D. Catoor, E.H. Chang, E.P. George, and R.O. Ritchie, A Fracture-Resistant High-Entropy Alloy for Cryogenic Applications, Science, 2014, 345, p 1153-1158

71. ASM metals handbook. Metals Park, OH: American Society for Metals; 1985

72. K.A. Rozman, M. Detrois, P.D. Jablonski, J.A. Hawk. Mechanical Performance of Various INCONEL ${ }^{\circledR} 740 / 740 \mathrm{H}$ Alloy Compositions for Use in A-USC Castings, in Proceedings of the 9th International Symposium on Superalloy 718 \& Derivatives: Energy, Aerospace, and Industrial Applications (Springer, 2018). p. 611-627

Publisher's Note Springer Nature remains neutral with regard to jurisdictional claims in published maps and institutional affiliations. 